DOI: https://doi.org/10.15517/rce.v36i1.33856

\title{
CALIDAD DEL EMPLEO Y MIGRACIÓN INTERNA EN COLOMBIA EN 2015
}

\author{
Alberto Castillo Aroca ${ }^{1}$ \\ Adelaida Patricia Acosta Betancourt ${ }^{2}$
}

Recibido: 16/09/2017

Aprobado: 21/05/2018

\section{RESUMEN}

\begin{abstract}
En el presente estudio se calculó un Índice Compuesto de Calidad del Empleo (ICCE) para los de-partamentos de Colombia, distinguiendo entre zonas urbanas y rurales. Para ello, se utilizaron datos de la Gran Encuesta Integrada de Hogares (GEIH) de los años 2014 y 2015. Posteriormente, se em-plearon modelos de regresión de respuesta binaria (logit y probit) para determinar cómo los subín-dices referentes a las dimensiones del ICCE explican la decisión de migrar de la PEA de Colombia a través del país.

Los resultados indican que el empleo de calidad predomina en las zonas urbanas, destacándose el liderazgo de Bogotá y Medellín. Por otro lado, los datos obtenidos señalan que tanto el ICCE como sus componentes fueron significativos al momento de explicar los patrones migratorios internos de Colombia.
\end{abstract}

PALABRAS CLAVE: CALIDAD DE VIDA, MERCADO LABORAL, AMBIENTE LABORAL, MIGRACIÓN INTERNA.

CLASIFICACIÓN JEL: J61, I31, R23

\section{ABSTRACT}

In the current study a Composite Index of Employment Quality (CIEQ) was calculated for the departments of Colombia, distinguishing between urban and rural areas. For this purpose, data from the, Great Integrated Survey of Households (GEIH) for the years 2014 and 2015 was used. Subsequently, regression models for binary outcomes (logit and probit) were used to determine how the sub-indexes concerning to the dimensions of the CIEQ explain the decision to migrate from the EAP of Colombia across the country.

The results indicate that the employment quality predominates in urban areas, highlighting the leadership of Bogota and Antioquia (Medellín). On the other hand, the data obtained indicate that both the CIEQ and their components were significant to explain the internal migration patterns of Colombia.

KEYWORDS: QUALITY OF LIFE, LABOUR MARKET, LABOUR ENVIRONMENT, INTERNAL MIGRATION

JEL CLASIFICATION: J61, I31, R23

1 Universidad Santo Tomás. Centro de Investigaciones Económicas Louis Joseph Lebret de la Facultad de Economía y Observatorio Latinoamericano de Desarrollo Sostenible OLDS. Código Postal: 110231426. Bogotá D.C., Colombia.

albertocastillo@usantotomas.edu.co y subdireccion@olds2030.org

2 Universidad Santo Tomás. Facultad de Gobierno y Relaciones Internacionales, Facultad de Negocios Internacionales y Observatorio Latinoamericano de Desarrollo Sostenible OLDS. Código Postal: 110221209. Bogotá D.C., Colombia.

adelaida.acosta@usantotomas.edu.co e internacional@olds2030.org 


\section{INTRODUCCIÓN}

Este trabajo utilizó datos de la Gran Encuesta Integrada de Hogares (GEIH) de 2014 y 2015, la cual fue elaborada por el Departamento Administrativo Nacional de Estadística (DANE) de Colombia para comprobar si las diferencias en materia de calidad del empleo, que se presentan en las zonas urbanas y rurales de los departamentos de dicho país, influyen de forma significativa en la decisión de migrar de la Población Económicamente Activa (PEA) de este.

En este sentido, la investigación intenta comprobar la siguiente hipótesis: "a la hora de migrar, las personas pertenecientes a la PEA no solo evalúan los retornos monetarios esperados de esta decisión, sino que adicionalmente evalúan los retornos no monetarios derivados de la calidad del empleo", entre los cuales se podría mencionar la mayor compatibilidad entre la jornada laboral y la vida familiar, la satisfacción laboral, la seguridad social, entre otros.

Para tal fin, el estudio parte del supuesto de racionalidad que implica que tanto los migrantes como los no migrantes conocen las características en cuanto a calidad del empleo de su entorno laboral y del promedio nacional o de otros departamentos. Por tal motivo, se asume que las personas residentes en regiones con una calidad del empleo por debajo de la media nacional tienen un incentivo a migrar hacia áreas con mayor calidad promedio, ceteris paribus.

Por consiguiente, para cumplir con el objetivo de la investigación, el estudio se dividió en dos etapas. En la primera fase, se estimó un Índice Compuesto de Calidad del Empleo (ICCE) como sumatoria de los subíndices de ocho ${ }^{3}$ dimensiones referentes al empleo de calidad. Dichas dimensiones fueron estimadas a partir de 49 indicadores seleccionados de la encuesta, siguiendo las observaciones de la OCDE (2008), Quiñones (2011), Pineda y Acosta (2011) y Boccuzzo y Gianecchini (2012). Posteriormente, en la segunda fase, se estimaron modelos logit y probit que utilizan una variable binaria como dependiente, la cual toma el valor de uno (1) si la persona migró en los últimos 12 meses o cero (0) en caso contrario. Esta es explicada por los ocho subíndices concernientes a las dimensiones de la calidad del empleo, con lo cual se puede evaluar la significancia estadística de las mismas a la hora de explicar la migración.

El estudio resulta pertinente debido a que organizaciones como el PNUD (2016) han identificado que, a pesar de los importantes esfuerzos por cumplir las Metas del Milenio para 2015 que gran parte de los países de Latinoamérica y el Caribe realizaron, cerca de 30 millones de personas en la región se encuentran en riesgo de caer en la pobreza y sumarse a los 175 millones de pobres que ha identificado la CEPAL (2016) en la región. Este hecho se adiciona a las serias desigualdades entre las zonas urbanas y rurales, lo cual supone una preocupante vulnerabilidad y fragilidad económica.

Por tal motivo, organismos como la CEPAL (2016) han resaltado la necesidad de cerrar las brechas entre las regiones urbanas y rurales por medio de la distribución y la generación de oportunidades en estas últimas. Así mismo, la OIT (1999), CEPAL (2016), PNUD (2016), entre otros, han instado a los distintos Gobiernos de Latinoamérica y el Caribe a aunar esfuerzos para incrementar la calidad del empleo en vista de que no todos los tipos de trabajo cumplen con satisfacer las necesidades básicas de los trabajadores y sus familias. Esto se ha visto reflejado en la inclusión, en 2008, de la meta 1B: lograr el empleo pleno y productivo y el trabajo decente para todos, incluidos las mujeres y los jóvenes, en la meta 1: erradicar la pobreza y el hambre, de los Objetivos de Desarrollo del Milenio (ODM) (Weller y Roethlisberger, 2011), así como en el establecimiento del objetivo 8: promover el crecimiento económico sostenido, inclusivo y sostenible, el empleo pleno y produc-

3 Las dimensiones establecidas son: satisfacción con el empleo; equidad de género; salud y seguridad social; inclusión al mercado laboral; diálogo social entre la empresa y el/la trabajador/a; estabilidad en el puesto de trabajo; jornada laboral y vida familiar/personal; e ingresos y ganancias laborales.son redimibles o rescatables directamente por el fondo en cualquier momento, siendo su plazo de duración indefinido. Los fondos cerrados se caracterizan por tener un patrimonio inicial determinado y una duración previamente establecida, siendo sus cuotas de participación colocadas entre el público no redimibles o rescatables directamente por el fondo, salvo en las circunstancias y procedimientos dispuestos específicamente por sus reglamentos internos" (SAFI BISA, 2018, párr. 1-4). 
tivo y el trabajo decente para todos, y el objetivo 11: lograr que las ciudades y los asentamientos humanos sean inclusivos, seguros, resilientes y sostenibles, como metas de los nuevos Objetivos de Desarrollo Sostenible (ODS).

Por otro lado, la migración interna en Colombia se correlaciona con las brechas socioeconómicas y laborales que se presentan en las zonas urbanas y rurales de los departamentos del país, ya que los migrantes encuentran motivaciones para buscar suplir sus necesidades insatisfechas en sus regiones de origen por medio de la migración (Gutierrez, Guzmán y Jiménez, 2000), con lo cual se generan cambios en la composición demográfica y económica de las zonas de origen y destino (Pizzolitto, 2006).

Este tipo de cambios pueden implicar efectos positivos en las zonas de destino, debido a que los migrantes generalmente cuentan con ciertas características deseables, en términos de selectividad, como una menor aversión al riesgo, mayor adaptabilidad (Pizzolitto, 2006), educación, juventud $y$ voluntad de trabajo, mientras que su arribo a ciertas zonas contribuye a la reducción en las disparidades de ingresos (Galvis, 2002). No obstante, dicha migración también afecta a las regiones de origen debido a que se reduce la fuerza laboral local y se producen desbalances en el nivel educativo promedio de la población (Todaro, 1980).

En consecuencia, la migración puede ser tanto un factor de desarrollo para las zonas céntricas, debido a que esta genera un incremento de la fuerza laboral disponible, como un elemento de atraso para las regiones de origen de los migrantes, a causa de la reducción de la oferta de trabajo y el capital humano.

Por otro lado, la realidad colombiana cuestiona estos supuestos, ya que los flujos migratorios no siempre se orientan hacia las áreas con mayor tasa de ocupación (Granados, 2010), lo cual genera fenómenos como el incremento del desempleo (Pradilla, 2016), la violencia y criminalidad en las regiones de destino. En este sentido, la migración interna podría suponer un efecto doblemente negativo, tanto para las regiones de origen como de destino.

En consecuencia, resulta de especial importancia para el desarrollo regional clarificar las características de los mercados laborales locales y los factores que motivan la migración para, de esta forma, aportar evidencia empírica que contribuya a la formulación de política pública e iniciativas privadas que contribuyan a generar oportunidades laborales, mejoría en las condiciones de vida en las regiones periféricas y orientar el desarrollo de forma deseable por la sociedad (Todaro, 1980), para así alcanzar la décimo primer meta de los Objetivos de Desarrollo Sostenible: lograr que las ciudades y los asentamientos humanos sean inclusivos, seguros, resilientes y sostenibles y cumplir con las reiteradas recomendaciones de la OIT (1999), PNUD (2016) y CEPAL (2016).

De igual modo, es importante resaltar que esta investigación es la primera en incluir los retornos monetarios y no monetarios derivados del trabajo como determinantes de la migración laboral, desde el marco teórico de la calidad del empleo. En tal sentido, el estudio realiza importantes aportes a las teorías de movilidad poblacional $y$ de factores productivos.

El presente documento se divide de la siguiente forma: la introducción; el marco teórico sobre calidad del empleo y migraciones; una breve revisión de la literatura; la metodología; los resultados; las conclusiones sobre la investigación; $y$ los agradecimientos.

\section{MARCO TEÓRICO}

\section{Calidad del empleo}

El estudio utiliza el concepto de calidad del empleo como punto de partida para analizar las condiciones de trabajo de las personas en los departamentos de Colombia. Según, Weller y Roethlisberger (2011), dicho concepto es dinámico y multifacético y no puede ser reducido a una sola variable. De igual modo, se asume que un empleo de calidad se caracteriza por cubrir las necesidades básicas 
de los trabajadores, es elegido en libertad, permite el crecimiento tanto personal como profesional de estos, entre otros. Así pues, las variables utilizadas para analizarlo deben reflejar de manera inequívoca la dirección de cambios en dichos aspectos (Arranz, García-Serrano, y Hernaz, 2016).

Por otro lado, es importante destacar que la calidad del empleo se diferencia de lo que se entiende por trabajo decente (OIT, 1999) ya que este último enfatiza la necesidad de un entorno favorable para la generación de empleo que si bien ayuda a la mejora de la calidad de esto, no la representa completamente ${ }^{4}$ (OIT, 2008).

Así mismo, se encuentran diferencias con el concepto de calidad del puesto de trabajo, el cual está relacionado con el proceso productivo y con una combinación específica de los factores de producción en la cual inciden la normatividad y el clima organizacional. En ese sentido, la calidad del puesto de trabajo también puede considerarse como condición necesaria, pero no suficiente para una buena calidad del empleo (Weller y Roethlisberger, 2011).

En cuanto a la medición de la calidad del empleo, se requiere que los indicadores cumplan tres aspectos: comparabilidad, fiabilidad y consistencia. Por otro lado, su medición se puede hacer desde diversos enfoques como: el subjetivo ${ }^{5}$ donde la calidad del empleo es observada de acuerdo a la satisfacción que cada persona siente con su trabajo; el objetivo, que considera que la calidad del empleo está constituida por las características observables de este; $y$ finalmente, el mixto que involucra ambas perspectivas. Estos enfoques se fundamentan en la literatura teórica y empírica de las ciencias sociales (economía, sociología y psicología) para identificar los elementos esenciales de la calidad del empleo (Muñoz de Bustillo, Fernández-Macías, Antón y Esteve, 2011; Peycheva, Wetzels, Parent-Thirion $y$ van Houten, 2014).

En este orden de ideas, esta investigación utiliza un enfoque mixto, debido a que incluye variables tanto objetivas como subjetivas para cuantificar la calidad del empleo de la población ocupada en Colombia, de una forma multidimensional que será explicada a mayor profundidad en la sección de la metodología

\section{Migración interna}

De acuerdo con Todaro (1980), Pizzolitto (2006) y Haug, 2008, existe una amplia literatura relacionada al estudio de las migraciones, debido a que esta provoca cambios importantes en la estructura demográfica de las regiones, lo cual genera un impacto importante en las dinámicas económicas.

No obstante, a pesar de la amplia gama de estudios realizados en esta temática, estos pueden ser catalogados de acuerdo a los enfoques que emplean. En este sentido, se pueden destacar principalmente la utilización de las Leyes de Ravenstein (1885), la teoría neoclásica del capital humano, la economía regional, el capital social y las redes sociales.

En cuanto a las Leyes de Ravenstein (1885), estas indican que existen factores específicos que motivan a las personas a emigrar y a seleccionar determinadas regiones como destino, con lo cual se pueden observar tendencias consistentes en todos los países. Entre estas se pueden destacar:

(i) la propensión de la población rural a migrar hacia zonas urbanas;

(ii) la correlación negativa entre migración y distancia;

(iii) la relación inversa entre los costos de transporte y la migración;

(iv) la tendencia de los migrantes urbanos a trasladarse entre zonas metropolitanas, es decir a generar un desplazamiento interurbano;

4 El trabajo decente se entiende como trabajo productivo en condiciones de libertad, equidad, seguridad y dignidad, en el cual los derechos son protegidos y que cuenta con remuneración adecuada y protección social.

5 Es subjetiva en el sentido de que cada trabajador tiene preferencias sobre las distintas características de los puestos de trabajo. 
(v) la doble condición de emigrante-inmigrante de las personas, lo cual implica que cada flujo migratorio presenta una corriente contraria que lo compensa; $y$

(vi) los factores económicos no son necesariamente los motivos dominantes en la decisión de migrar, ya que se ha comprobado que características como la calidad de vida, la violen cia, la cultura, entre otros, también tienen un efecto importante en las decisiones indivi duales de migración.

La teoría neoclásica del capital humano asume la decisión de migrar como un proceso racional, en el cual dicha decisión constituye una inversión en capital humano, debido a que la experiencia de migrar adiciona habilidades, conocimientos y experiencias de la nueva ocupación al stock de capital humano previamente existente (Haug, 2008). En tal sentido, la decisión de migrar se realiza tras un análisis costo-beneficio de dicha inversión, teniendo en cuenta las diferencias salariales, el salario esperado, los costos de transporte, alojamiento y adaptación al medio, el tiempo de traslado, la infraestructura, el clima, la seguridad, entre otros (Galvis, 2002; Pizzolitto, 2006).

Entre los resultados de los estudios aplicados con este enfoque, se puede destacar que la gran mayoría confirma las hipótesis de Todaro (1969;1980), según el cual:

- la decisión de migrar obedece principalmente a consideraciones económicas racionales que se traducen en un análisis de costo-beneficio, que también incluye aspectos psicológicos;

- la decisión de migrar depende principalmente de las expectativas de los retornos a recibir antes que en las diferencias actuales entre el ingreso percibido en las regiones de origen y destino;

- la expectativa o probabilidad de obtener un empleo en las regiones de destino es directamente proporcional a la tasa de ocupación en las mismas;

- cuando las tasas de migración exceden la capacidad de las regiones de destino para generar empleo se generan serios desequilibrios que generan desempleo;

De este modo, si una persona percibe que obtendrá retornos de acuerdo con su stock de capital humano y las características de la región de destino, se podría esperar que esta migre, ceteris paribus. No obstante, cuando existen aspectos que pueden reducir las probabilidades de obtener un empleo se podría esperar una anulación de los incentivos iniciales y que se desaliente la migración. Este es el caso de aspectos como la edad, ya que el flujo esperado de retornos netos que esperan los migrantes se reduce a medida que estos envejecen.

Por otra parte, la economía regional establece que existe una relación entre migraciones y desarrollo económico. Sin embargo, el signo de esta relación es ambiguo, debido a que los efectos pueden ser tanto positivos como negativos. En cuanto a los efectos positivos, estos generalmente se establecen en términos de selectividad de la persona migrante, es decir, las personas que se autoseleccionan para migrar generalmente presentan una serie de características positivas y deseables para sus regiones de destino. Entre estas se puede destacar el dinamismo, su menor aversión al riesgo, su propensión a emprender y una mayor adaptabilidad (Pizzolitto, 2006). No obstante, entre los efectos negativos se puede citar que las migraciones generan una reducción de la fuerza laboral en las regiones de origen, variaciones importantes en el nivel de escolaridad, cambios demográficos y de acuerdo con las condiciones laborales de las regiones de destino, los migrantes pueden generar un incremento en la criminalidad, violencia y desempleo (Galvis, 2002). Otro enfoque se refiere a la economía de la información. Dicha perspectiva defiende el rol de la información, el capital social y las redes sociales en la toma de decisiones en cuanto a la opción de migrar. En este sentido, mientras otros enfoques privilegian variables a nivel micro o macro, este ofrece una visión sistémica que incluye el nivel meso (Faist, 1997) a los ya mencionados, en este orden de ideas se introducen variables que vinculan las estructuras sociales a nivel macro con el individuo a nivel micro. Es decir, se incorporan aspectos como las redes de parentesco familiar, 
redes sociales, redes de migrantes, vinculación a una comunidad, autonomía, entre otras (De Jong y Fawcett, 1981), con lo cual se coloca al individuo en un entramado social que condiciona sus decisiones (Boyd, 1989) .

Los estudios que han aplicado este enfoque destacan que el capital social y los contactos en las regiones de destino tienden a reducir la incertidumbre de los posibles migrantes y generan redes de apoyo para ubicar laboral y habitacionalmente a estos. De igual modo, destacan que si bien la elección racional individualista de la migración como un análisis de costo-beneficio es acertada, en ocasiones su alcance es limitado; ya que se ha demostrado que frecuentemente la función de ingresos o retornos que se maximiza es una función agregada del hogar (Stark, 1991), lo cual, al no ser previsto puede generar sesgos y resultados contra-intuitivos para la perspectiva individualista.

En el presente estudio, se utiliza la teoría del capital humano de corte neoclásica, debido a que la hipótesis refiere a un análisis costo-beneficio que se pretende comprobar por medio de modelos logit y probit de respuesta binaria. Por otro lado, se prescinde de la utilización de las Leyes de Ravestein y los enfoques de la economía regional y las redes sociales, dado que sus aportes trascienden las necesidades de la investigación. No obstante, se recomienda su inclusión en estudios posteriores.

Cabe destacar que la presente investigación se diferencia de otras por ser la primera en incluir los retornos monetarios y no monetarios derivados del trabajo desde la perspectiva teórica de la calidad del empleo como determinantes de la migración laboral, lo cual implica importantes aportes a las teorías de la movilidad de las poblaciones y de los factores productivos.

\section{REVISIÓN DE LITERATURA}

\section{Calidad del empleo como marco conceptual para evaluar las condiciones laborales}

Tras constatar que el mercado laboral presenta importantes diferencias cualitativas en cuanto a las características del trabajo, la OIT (1999) desarrolló el concepto de "trabajo decente", entendido como el empleo que asegura una vida digna para los trabajadores, tras observar que a pesar del incremento de los puestos laborales y la reducción del desempleo, una importante proporción de la fuerza laboral permanecía en una situación de pobreza, vulnerabilidad y exclusión (Weller y Roethlisberger, 2011; Weller, 2012).

Como resultado de estos esfuerzos teóricos, un creciente grupo de economistas adquirió un interés particular por las condiciones laborales y las características que implican que un empleo sea de calidad (Reinecke y Valenzuela, 2000). Por tal motivo, en las últimas décadas han proliferado las investigaciones sobre la calidad de los puestos de trabajo y la calidad del empleo ${ }^{6}$, las cuales pueden ser catalogadas de acuerdo a la metodología utilizada en: estudios con indicadores unidimensionales, estudios con índices compuestos y estudios multidimensionales con variables latentes.

El presente estudio se adhiere a la tendencia de utilizar índices compuestos para evaluar la calidad del empleo. Las investigaciones de dicha corriente se caracterizan por clasificar la amplia gama de indicadores relativos a las características de los empleos en un conjunto de dimensiones, a partir de las cuales se construye un índice sintético que expresa de forma cuantitativa el grado de calidad del empleo en los sectores económicos o zonas urbanas y rurales de un determinado país.

Sin embargo, es importante resaltar que los aspectos metodológicos de los índices imponen ciertas limitaciones, específicamente se puede resaltar que estos son ponderados para obtener el resultado final, lo cual provoca discrepancias, debido a que no existe consenso sobre las ponderaciones a utilizar. Por otro lado, generalmente se realiza una estandarización de las variables con respecto al promedio de una muestra que suele obtenerse de un país en concreto.

6 La diferencia entre ambos conceptos es enunciada en el marco teórico. 
Por tal motivo, la normalización de las variables se realiza con respecto a la media nacional de estas (Dueñas, Iglesias y Llorente, 2009), lo cual imposibilita frecuentemente las comparaciones internacionales (Quiñones, 2011).

Weller y Roethlisberger (2011) destacan que una limitación adicional de los índices compuestos es su tendencia a ocultar el empeoramiento de alguna variable por medio de efectos compensatorios con otras. Adicionalmente, plantea la necesidad de no establecer una plantilla rígida para todos los países, debido a que la calidad del empleo es una categoría dinámica y la importancia de sus dimensiones varía a lo largo del tiempo. Sin embargo, resaltan que la utilidad de un índice consiste en la facilidad que se logra para comunicar la evolución de la calidad del empleo como un concepto general y la posibilidad de observar tendencias de largo plazo. Por otro lado, según Boccuzzo y Gianecchini (2012), los índices compuestos también poseen una función gerencial o administrativa, debido a que permiten tomar decisiones de acuerdo con estos.

Entre las investigaciones que hacen uso de índices compuestos se pueden destacar las llevadas a cabo por: Farné (2003), Farné y Vergara (2007), Dueñas, Iglesias y Llorente (2009), Quiñones (2011), Pineda y Acosta (2011), Farné, Vergara y Baquero (2012), Farné (2012), Gómez, Galvis-Aponte y Royuela (2015) en Colombia; Casanueva y Rodríguez (2009) en México; Sehnbruch (2012) en Chile; Boccuzzo y Gianecchini (2012) en Italia; y Arranz, García-Serrano y Hernanz (2016) en España.

Cabe destacar que estos estudios no son completamente homogéneos y que los componentes seleccionados como determinantes de la calidad laboral difieren de una investigación a otra. Entre las dimensiones más utilizadas para construir los índices compuestos se encuentran las siguientes: satisfacción en el trabajo, ingreso laboral, salud y seguridad física y social, flexibilidad de la jornada laboral, inclusión y acceso al trabajo, equilibrio entre la vida laboral y personal, equidad de género, entorno económico, capacitación laboral y oportunidades de ascenso y diálogo social.

Por otro lado, entre los resultados más recurrentes destaca un empeoramiento de la calidad del trabajo y la proliferación de trabajos de baja calidad, así como que las zonas metropolitas, principalmente las capitales, tienden a mostrar índices de calidad del empleo más altos en comparación con las rurales; sin embargo, la alta heterogeneidad de los mismos dificulta su comparación.

Con respecto a la influencia de dichos estudios sobre el presente artículo, sobresale el trabajo realizado por Quiñones (2011), el cual guarda una estrecha similitud metodológica. Dicho artículo clasifica a las áreas metropolitanas colombianas de acuerdo con su nivel de calidad del empleo. Según los resultados obtenidos, Medellín (Antioquia), Cali (Valle del Cauca), Bucaramanga (Santander), Barranquilla (Atlántico) y Bogotá se posicionan como las ciudades con mayor calidad del empleo.

\section{Relación entre la migración interna y la calidad del empleo}

Al tratar la movilidad de factores productivos en los modelos económicos, habitualmente se asume que el principal elemento que determina la migración laboral es el salario. Esto se puede observar en modelos como el de Factores Específicos (Krugman, Obstfeld y Melitz, 2012) y el Heckscher-Ohlin (López y Schiff, 1998), en los cuales se explica que la decisión de migrar se toma tras realizar un análisis costo-beneficio del retorno monetario que podría obtener un trabajador en una región diferente a la de su residencia inicial.

No obstante, diversos estudios han resaltado el carácter multidimensional de la migración, destacando que factores como los costos asociados a ella y los retornos no monetarios como la probabilidad de obtener un empleo, la infraestructura física, los servicios públicos, la seguridad, el clima, entre otros, son determinantes igualmente importantes en la decisión de migrar. 
En este sentido, Silva y González (2009) realizaron una exhaustiva revisión y clasificación de la literatura de acuerdo con las perspectivas utilizadas para analizar la migración en el país. Esta se resume en los resultados del cuadro 1. Así mismo, entre los aportes de estos autores también se encuentra el desarrollo de un modelo gravitacional, con el cual se pudo comprobar que los flujos migratorios se dirigen principalmente hacia las regiones más pobladas, con mayores ingresos e historia de acogida a migrantes.

Por otro lado, en la literatura colombiana habitualmente se aborda el desplazamiento forzado como un fenómeno de migración involuntaria, el cual es ocasionado por la violencia derivada del conflicto armado que sufre el país desde mediados del siglo XX. En este sentido, autores como Rubiano y Granados (1999) y Engel e Ibáñez (2007) han destacado que la violencia es un elemento importante a la hora de explicar la movilización de las poblaciones a lo interno del país.

Sin embargo, el presente estudio se centra en la migración laboral voluntaria y prescinde del análisis del desplazamiento forzado. Esta decisión fue tomada debido a que incluir las movilizaciones involuntarias puede ocasionar distorsiones en los resultados del estudio, ya que parte de un supuesto de racionalidad que implica la existencia de acciones ligadas al análisis de costo-beneficio y tendientes a la maximización de la utilidad.

Así mismo, la investigación presenta una marcada diferencia con referencia a los artículos anteriormente mencionados, debido a que incluye los retornos monetarios y no monetarios del empleo, los cuales son cuantificados desde el marco teórico relacionado a la calidad del empleo. En este sentido, la investigación se posiciona como precursora en la inclusión de las dimensiones de la calidad del empleo como determinantes de la migración laboral, lo cual implica un importante aporte a las teorías de migración y movilidad de factores productivos.

\section{METODOLOGÍA}

Para llevar a cabo la investigación, se eligió un enfoque inductivo, debido a que se utilizan microdatos anonimizados ${ }^{7}$ con el fin de ofrecer conclusiones generales sobre el efecto de las diferencias en calidad del empleo entre las zonas urbanas y rurales de los departamentos de Colombia en la decisión de migrar de la Población Económicamente Activa (PEA).

CUADRO 1

CLASIFICACIÓN DE ESTUDIOS SOBRE LOS DETERMINANTES DE LA MIGRACIÓN DE ACUERDO CON LAS VARIABLES UTILIZADAS

\begin{tabular}{|c|c|}
\hline \multicolumn{2}{|r|}{ COSTOS } \\
\hline Distancia & $\begin{array}{l}\text { Adams, 1969; Vanderkamp, 1971; Congdon, 1992; Martínez, 2001; Chacón, } \\
\text { 2004. Distancia a la capital | a los mercados principales: Chacón, 2004; } \\
\text { Sánchez y Díaz, 2005. Inverso de la distancia: Da Vanzo, } 1978 .\end{array}$ \\
\hline \multicolumn{2}{|r|}{ RETORNOS } \\
\hline \multicolumn{2}{|r|}{ INGRESOS } \\
\hline Ingresos o PIB & $\begin{array}{l}\text { Vanderkamp, 1968; Todaro, 1969; 1971; Lang, 1972; Greenwood, 1975; } \\
\text { Da Vanzo, 1978; Mincer, 1978; Morrison, 1993; Shefer y Steinvortz, 1993; } \\
\text { Osberg et. al, 1994; Yap, 1996; Aroca y Bosch, 2000. }\end{array}$ \\
\hline \multicolumn{2}{|r|}{ COSTOS Y OPORTUNIDADES LABORALES } \\
\hline Impuestos locales & Walker et. al, 1992. \\
\hline
\end{tabular}

7 Las respuestas anónimas ofrecidas por cada individuo en las encuestas de hogares. 


\section{COSTOS}

Mercado Laboral
- Diferenciales Salariales: Fields, 1975; Walker et. al, 1992; Osberg et. al,
1994. Salario mínimo: Yap, 1996.
- Tasa de crecimiento del empleo y desempleo: Vanderkamp, 1968; Lang,
1972; Fields, 1975; Greenwood, 1975; Da Van- zo, 1978; Schlottmann y
Herzog, 1981; Stark, 1991; Walker et. al, 1992; Shefer y Steinvortz, 1993;
Flórez, 2003; Chacón, 2004. Trabajo calificado | no calificado: Morrison,
1993; López y Schiff, 1998.
- Tasa de crecimiento de los ocupados orígenes | destino: Congdon, 1992,
Silva y Guataqui, 2006. Seguridad Social: Sánchez y Díaz, 2005.

Precios

Clima

Comercio

Educación

Mortalidad Infantil

Otras Características

Geográficas e Infraestructura

Población

Pobreza

Propiedad

Regiones

Sector

Transferencias e inversión municipal

Urbanización

Violencia
Precios de la vivienda origen | destino: Congdon, 1992; Walker et. al, 1992.

\section{CALIDAD DE VIDA}

Walker et. al, 1992.

Aranceles, exportaciones e importaciones: Borjas et. al, 1997; López y Schiff, 1998.

Adams, 1969; Greenwood, 1975; Shefer y Steinvortz, 1993; Osberg et. al, 1994; Borjas, et. al, 1997; Navarro y Méndez, 2002; Flórez, 2003; Chacón, 2004; Sánchez y Chacón, 2005; Sánchez y Díaz, 2005; Silva y Guataqui, 2006.

Sánchez y Díaz, 2005.

Vías y líneas telefónicas: Chacón, 2004; Sánchez y Díaz, 2005. Regiones:

Vanderkamp, 1968; Walker et. al, 1992.

Annable, 1972; Chacón, 2004. Origen | destino: Congdon, 1992.

NBI e ICV: Martínez, 2001; Chacón, 2004; Pérez, 2005; Sánchez y Chacón, 2005. Coeficiente de Gini | Línea de Pobreza: Martínez, 2001; Chacón, 2004.

Índice de Concentración de la Propiedad Privada: Sánchez y Díaz, 2005. Gini Avalúo de la Propiedad: Sánchez y Chacón, 2005.

Lang, 1972; Walter et. al, 1992.

- Agrícola o Industrial: Todaro, 1969; Lang, 1972; Osberg et. al, 1994.

Chacón, 2004; Sánchez y Chacón, 2005; Sánchez y Díaz, 2005.

- Tasa de Urbanización: Schultz, 1971; Annable, 1972; Shefer y Steinvortz, 1993; Yap, 1996; Martínez, 2001; Navarro y Méndez, 2002; Flórez, 2003.

- Número de Ciudades: Shaw, 1980

- Tasa de edificación residencial: Shaw, 1980.

- Tasa de homicidios: Walker et. al, 1992; Sánchez et. al, 2003; Chacón, 2004; Sánchez y Díaz, 2005. Específi-camente homicidios de candidatos y dirigentes políticos: Martínez, 2001; Sánchez y Chacón, 2005.

- Presencia de grupos armados ilegales: Sánchez et. al, 2003; Chacón, 2004; Sánchez y Chacón, 2005; Sánchez y Díaz, 2005; Martínez, 2001.

- Secuestros y ataques guerrilleros: Martínez, 2001; Sánchez et. al, 2003; Chacón, 2004; Sánchez y Chacón, 2005; Sánchez y Díaz, 2005. Ingreso del narcotráfico: Martínez, 2001; Sánchez et. al, 2003; Chacón, 2004.

- Eficiencia de la justicia medida como el número de capturas por homicidios: Martínez, 2001; Sánchez et. al, 2003; Chacón, 2004; Sánchez y Chacón, 2005.

- Número de policías por cada 100.000 habitantes: Martínez, 2001.

Fuente: Fuente: Silva y González (2009).

Nota: la referencia de los artículos citados se pueden consultar en el artículo original de Silva y González (2009), denominado "Un análisis espacial de las migraciones internas en Colombia (2000-2005)". 
Por otro lado, se decidió estimar un índice compuesto de calidad del empleo (ICCE) de acuerdo con las observaciones de Quiñones (2011), Pineda y Acosta (2011), Boccuzzo y Gianecchini (2012) y los lineamiento de la OCDE (2008). Posteriormente, los subíndices de las dimensiones del ICCE fueron empleadas en modelos de elección binaria (probit y logit) para estimar el efecto de calidad del empleo sobre la decisión de migrar de la PEA colombiana.

\section{Datos}

El presente estudio utiliza la Gran Encuesta Integrada de Hogares (GEIH), elaborada por el Departamento Administrativo Nacional de Estadística (DANE) de Colombia durante 2014-2015, contemplando a la Población Económicamente Activa (PEA), para las zonas urbano-rurales del país. Cabe destacar que la encuesta fue hecha por medio de muestreo probabilístico, multietápico, estratificado y por conglomerados, con lo cual se confirma su significancia estadística e idoneidad para el presente estudio.

Es importante resaltar que los datos de la GEIH son de carácter ex-post, es decir, solamente se puede observar la decisión de migrar cuando esta ya fue efectuada. Por tal motivo, se utilizó el capítulo de migraciones de la GEIH de 2015 para obtener la información de la PEA que migró 12 meses atrás, durante 2014. Este hecho impuso la necesidad de estimar el ICCE de dicho año, para lo cual se empleó la GEIH de 2014.

Finalmente, para estimar los modelos de elección binaria. se utilizaron los datos de la PEA migrante y no migrante de 2015,a la cual se le asignaron los subíndices referentes a cada dimensión de la calidad del empleo de acuerdo con su región de residencia 12 meses atrás, es decir en 2014.

\section{Índice de Calidad del Empleo}

Según Boccuzzo y Fordellone (2015), un índice compuesto es un promedio ponderado de las dimensiones constituyentes del objeto o concepto de estudio, las cuales, a su vez, son un promedio ponderado de sus indicadores. Esto se puede observar en la ecuación [1 ] donde j es la cantidad de dimensiones del Índice, $\alpha_{j}$ son las ponderaciones que reciben cada una, $H$ es la cantidad de indicadores $I_{h}$ que componen una dimensión $\mathrm{j}, y w_{h}$ son los pesos que recibe cada uno y $k$ hace referencia a la región urbana o rural de cada departamento.

$$
I C_{k}=\sum_{j=1}^{j} \alpha_{j}\left(\sum_{h=1}^{H} I_{h k} w_{h}\right)
$$

Fuente: Boccuzzo y Fordellone (2015)

Cabe destacar que cada indicador fue estimado a nivel departamental como un promedio del valor que presentó la Población Económicamente Activa (PEA) para este en dicha unidad territorial, como se puede observar en la ecuación [2], donde el h-indicador del k-departamento es el promedio presentado por los i-individuos residentes en el mismo.

$$
I_{h k}=\frac{\sum_{i=1}^{n} I_{h k i}}{n_{k}}
$$

Es importante resaltar que el Índice Compuesto de Calidad del Empleo (ICCE) fue estimado con fines descriptivos, ya que el interés fundamental del presente estudio es evaluar la influencia de las j-dimensiones sobre la decisión de migrar de los trabajadores. Por tal motivo se prescindió de realizar un análisis de componentes principales o utilizar otras metodologías para establecer las 
ponderaciones $\alpha_{j} y w_{h}$, por consiguiente, el ICCE fue estimado como una sumatoria simple de las j-dimensiones, asumiendo el mismo peso para cada una. Igualmente, cada dimensión fue calculada como la sumatoria de los indicadores $I_{h k}$, tomando la misma ponderación $w_{h}$ para cada uno.

En cuanto al método de estandarización de los indicadores $I_{h k}$, estos fueron transformados a la variable $z_{h k}$ de acuerdo con la ecuación [3], es decir, se calculó el valor de cada indicador para cada departamento en su versión urbana y rural, los cuales fueron comparados con respecto al promedio nacional por medio de una sustracción y divididos por la desviación estándar del propio indicador. Este método permite normalizar el valor de los indicadores, con lo cual se facilita la comparación entre los valores de estos.

$$
z_{h k}=\frac{\overline{I_{h k}}-\overline{I_{h}}}{\sigma_{h k}}
$$

Es importante resaltar que por consiguiente, la fórmula empleada en el presente estudio para estimar el ICCE es la ecuación [ 4 ]. Esta última tiene la particularidad de generar un ICCE normalizado con respecto a la media nacional, por lo cual si el ICCE o el subíndice para las j-dimensiones es negativo, se puede concluir que está por debajo de la media nacional y viceversa. Es importante aclarar que, con el objetivo de observar de una forma más detallada las diferencias en cuanto a calidad del empleo, los valores tipificados de los indicadores fueron multiplicados por 10.

$$
\operatorname{ICCE}_{i}=\sum_{j=1}^{j}\left(\sum_{h=1}^{H} z_{h k} * 10\right)
$$

Con respecto a las dimensiones y los indicadores utilizados se tuvieron en cuenta las observaciones y el criterio de Dueñas, Iglesias y Llorente (2009), Quiñones (2011), Pineda y Acosta (2011) y Gómez, Galvis-Aponte y Royuela (2015). No obstante, los autores decidieron seleccionar los siguientes:

CUADRO 2

DIMENSIONES DE LA CALIDAD DEL EMPLEO E INDICADORES

\begin{tabular}{llll} 
Dimensión & Indicador & Descripción & $\begin{array}{l}\text { Variable } \\
\text { GEIH }\end{array}$ \\
\hline Satisfacción con el empleo & satis_01 & Satisfecho/a con su trabajo & p7170s1 \\
& satis_02 & No desea cambiar el trabajo & ponforme con el contrato \\
& satis_03 & p6422 \\
& satis_04 & Satisfecho/a con los beneficios que recibe & p7170s5 \\
& satis_05 & Satisfecho/a con la jornada laboral & p7170s6 \\
& & & p6450 \\
& genero_01 & Proporción de mujeres con contrato escrito & p6450 \\
& genero_02 & Proporción de hombres con contrato escrito & inglabo \\
& genero_03 & Promedio del ingreso laboral de las mujeres & rama2d \\
genero_04 & Promedio del ingreso laboral de los hombres & rama2d \\
genero_05 & Proporción de mujeres en el Sector Primario & oci \\
genero_06 & Proporción de mujeres en el Sector Industrial & oc \\
\hline
\end{tabular}




\begin{tabular}{|c|c|c|c|}
\hline Dimensión & Indicador & Descripción & $\begin{array}{l}\text { Variable } \\
\text { GEIH }\end{array}$ \\
\hline Salud y Seguridad Social & $\begin{array}{l}\text { sayse_01 } \\
\text { sayse_02 } \\
\text { sayse_03 } \\
\text { sayse_04 } \\
\text { sayse_05 } \\
\text { sayse_06 } \\
\text { sayse_07 }\end{array}$ & $\begin{array}{l}\text { El trabajo no exige mucho esfuerzo físico y mental } \\
\text { En el trabajo no hay problemas ambientales } \\
\text { Afiliado/a a una caja de compensación familiar } \\
\text { Asegurado/a a una ARL }{ }^{8} \\
\text { Proporción de personas cotizando pensiones } \\
\text { Años cotizando pensiones } \\
\text { Afiliado a una EPS } 9\end{array}$ & $\begin{array}{l}\text { p7140s7 } \\
\text { p7140s8 } \\
\text { p9450 } \\
\text { p6990 } \\
\text { p6920 } \\
\text { p6960 } \\
\text { p6915 }\end{array}$ \\
\hline $\begin{array}{l}\text { Inclusión al mercado } \\
\text { laboral }\end{array}$ & $\begin{array}{l}\text { inclu_01 } \\
\text { inclu_02 } \\
\text { inclu_03 } \\
\text { inclu_04 } \\
\text { inclu_05 } \\
\text { inclu_06 } \\
\text { inclu_07 } \\
\text { inclu_08 } \\
\text { inclu_09 }\end{array}$ & $\begin{array}{l}\text { Proporción de ocupados } \\
\text { Proporción de trabajadores con un trabajo previo } \\
\text { Años desempleado antes del trabajo actual } \\
\text { Años en el empleo anterior } \\
\text { Meses que trabajó en el año } \\
\text { Quiere trabajar más horas } \\
\text { Proporción de trabajadores en el sector Industrial } \\
\text { Proporción de trabajadores en el sector Servicios } \\
\text { Proporción de trabajadores en el sector Primario }\end{array}$ & $\begin{array}{l}\text { oci } \\
\text { p7020 } \\
\text { p760 } \\
\text { p7026 } \\
\text { p6790 } \\
\text { p6915 } \\
\text { rama2d } \\
\text { rama2d } \\
\text { rama2d }\end{array}$ \\
\hline Diálogo social & $\begin{array}{l}\text { dialog_01 } \\
\text { dialog_02 }\end{array}$ & $\begin{array}{l}\text { Afiliado/a a sindicato } \\
\text { Proporción de trabajadores contratados por la empresa } \\
\text { donde trabajan y no por una tercera }\end{array}$ & $\begin{array}{l}\text { p7180 } \\
\text { p6400 }\end{array}$ \\
\hline $\begin{array}{l}\text { Estabilidad en el puesto de } \\
\text { trabajo }\end{array}$ & $\begin{array}{l}\text { establ_01 } \\
\text { establ_02 } \\
\text { establ_03 } \\
\text { establ_04 } \\
\text { establ_05 } \\
\text { establ_06 }\end{array}$ & $\begin{array}{l}\text { Proporción de personas que consideran que su trabajo es } \\
\text { estable } \\
\text { Proporción de personas que consideran que su trabajo es } \\
\text { permanente } \\
\text { Proporción de personas con contrato indefinido } \\
\text { Promedio de años trabajando en el empleo actual } \\
\text { Proporción de personas con contrato escrito } \\
\text { Proporción de personas que trabajan por cuenta propia }\end{array}$ & $\begin{array}{l}\mathrm{p} 514 \\
\mathrm{p} 6780 \\
\mathrm{p} 6460 \\
\mathrm{p} 6426 \\
\mathrm{p} 6450 \\
\mathrm{p} 6430\end{array}$ \\
\hline $\begin{array}{l}\text { Jornada laboral } y \text { vida } \\
\text { familiar/personal }\end{array}$ & $\begin{array}{l}\text { establ_01 } \\
\text { establ_02 } \\
\text { establ_03 } \\
\text { establ_04 } \\
\text { establ_05 } \\
\text { establ_06 }\end{array}$ & $\begin{array}{l}\text { Proporción de personas con una jornada laboral } \\
\text { compatible con su vida familiar y/o personal } \\
\text { Proporción de personas que no desea trabajar menos horas } \\
\text { Proporción de personas sin un segundo trabajo } \\
\text { Proporción de personas que trabaja entre } 40 \text { y } 48 \text { horas } \\
\text { semanales } \\
\text { Proporción de personas que trabaja menos } 40 \text { porque así } \\
\text { lo desea }\end{array}$ & bolivianos \\
\hline $\begin{array}{l}\text { Ingresos y ganancias } \\
\text { laborales }\end{array}$ & $\begin{array}{l}\text { ingreyga_01 } \\
\text { ingreyga_02 } \\
\text { ingreyga_03 } \\
\text { ingreyga_04 } \\
\text { ingreyga_05 } \\
\text { ingreyga_06 }\end{array}$ & $\begin{array}{l}\text { Ingreso real de las personas } \\
\text { Ingreso real por el segundo trabajo } \\
\text { Proporción de personas que reciben primas } \\
\text { Proporción de personas que tienen derecho a cesantías } \\
\text { Proporción de personas que reciben vacaciones pagas } \\
\text { Proporción de personas que reciben pagos por horas extra }\end{array}$ & $\begin{array}{l}\text { inglabo } \\
\text { p7070 } \\
\text { p6545 } \\
\text { p6424s3 } \\
\text { p6424s1 } \\
\text { p6510 }\end{array}$ \\
\hline
\end{tabular}

Fuente: Fuente: Elaboración propia con datos de la GEIH.

8 Aseguradora de Riesgos Laborales (ARL)

9 Empresa Promotora de Salud (EPS) 
Es importante resaltar que para elaborar los subíndices para cada dimensión y el ICCE se utilizaron los promedios y proporciones estandarizadas de cada indicador para las zonas urbanas $y$ rurales de 23 departamentos de Colombia más Bogotá, D.C.

Adicionalmente, se realizaron algunos cálculos en la dimensión Equidad de Género para establecer las brechas entre hombres y mujeres en términos de proporción trabajadores con contrato escrito, diferencia en el ingreso laboral y proporción de ocupados. En tal sentido se utilizaron como indicadores del subíndice para dicha dimensión la diferencia entre genero_01 y genero_02; genero_03 y genero_04; y genero_08 y genero_09 respectivamente.

Con respecto a los departamentos, se tomaron en cuenta los siguientes:

CUADRO 3

DEPARTAMENTOS SELECCIONADOS PARA EL ESTUDIO

\begin{tabular}{lrrrrr}
\hline Departamento & Divipola & Capital & Departamento & Divipola & Capital \\
\hline Antioquia & 05 & Medellín & Huila & 41 & Neiva \\
Atlántico & 08 & Barranquilla & La guajira & 44 & Riohacha \\
Bogotá & 11 & Bogotá & Magdalena & 47 & Santa Marta \\
Bolívar & 13 & Cartagena & Meta & 50 & Villavicencio \\
Boyacá & 15 & Tunja & Nariño & 52 & Pasto \\
Caldas & 17 & Manizales & Norte de Santander & 54 & Cúcuta \\
Caquetá & 18 & Florencia & Quindío & 63 & Armenia \\
Cauca & 19 & Popayán & Risaralda & 66 & Pereira \\
Cesar & 20 & Valledupar & Santander & 68 & Bucaramanga \\
Córdoba & 23 & Montería & Sucre & 70 & Sincelejo \\
Cundinamarca & 25 & Bogotá & Tolima & 73 & Ibagué \\
Chocó & 27 & Quibdó & Valle del cauca & 76 & Cali \\
\hline
\end{tabular}

Fuente: Elaboración propia con datos del DANE.

Se prescindió de analizar los departamentos Amazonas, Arauca, Casanare, Guainía, Guaviare, Putumayo, San Andrés y Providencia, Vaupés y Vichada por falta de datos.

\section{Supuesto de la investigación}

La investigación parte del supuesto de que tanto los migrantes como los no migrantes conocen las características en cuanto a calidad del empleo de su entorno laboral, del promedio nacional y de las otras zonas.

10 División Político Administrativa 
Por tal motivo se asume una utilidad $U_{k i}$ para los i-individuos en las k-zonas, la cual depende de las j-dimensiones de la calidad del empleo y las características de cada persona.

Partiendo del supuesto de racionalidad, se espera que los i-individuos intenten maximizar su utilidad. Por tal motivo, si los i-individuos conocen la magnitud de su utilidad $U_{k i}$ y el contexto laboral promedio nacional donde podrían obtener una utilidad de $\bar{U}$, se espera que los i-individuos que perciban una utilidad $U_{k i}$ inferior a la media nacional $\bar{U}$ tengan una motivación para migrar, ceteris paribus.

$$
P i= \begin{cases}1 & \text { si } U_{k i}<\bar{U} \\ 0 & \text { si } U_{k i}>\bar{U}\end{cases}
$$

Por consiguiente, el conjunto de elección que se evalúa en la presente investigación es binario $(1,0)$ y corresponde a la decisión de migrar o no por parte de la PEA colombiana en el año 2014 y observada con carácter ex post en el año 2015.

Cabe destacar que el mencionado conjunto de elección cumple con las características necesarias para estimar modelos de elección binaria. Debido a que cumple con el requisito de que las alternativas sean mutuamente excluyentes, el conjunto es exhaustivo -es decir que incluye todas las opciones posibles - y el número de alternativas es finito (Train, 2009).

De igual modo, es importante destacar que debido a que los investigadores no pueden cuantificar la magnitud de la utilidad de cada individuo, estos utilizan un conjunto de variables $c_{k}$ relativas a las características de cada opción del conjunto de elección y cualidades $s_{i}$ propias de los individuos. Con estas es posible establecer una relación entre los aspectos observados con la decisión tomada por los individuos (Train, 2009) dando lugar a la siguiente representación de la utilidad:

$$
\begin{aligned}
& U_{k i}=V_{k i}+\varepsilon_{k i} \\
& V_{k i}=V\left(c_{k}, s_{i}\right)
\end{aligned}
$$

Donde la utilidad real es observada a través de una función de utilidad definida por los atributos mencionados, destacándose que existe un error en dicha observación de magnitud $\varepsilon_{k i}$. Por otro lado, la función cuantificable $V_{k i}$ depende de $c_{k}$, el cual corresponde a las dimensiones del ICCE. Mientras que $s_{i}$ hace referencia a características individuales.

$$
c_{k}=\sum_{j=1}^{8} C E_{j k}
$$

Por consiguiente, la función utilidad asumida corresponde a:

$$
U_{k i}=V_{k i}+\varepsilon_{k i}=\alpha+\beta_{j k} \sum_{j=1}^{8} I C C E_{j k}+\beta_{p} \sum_{p=1}^{p} s_{i}+\varepsilon_{k i}
$$

Gracias a los modelos de elección binaria se podrá establecer la influencia de cada dimensión del ICCE sobre la probabilidad de migrar y por consiguiente sobre la decisión de migrar.

En la siguiente sección se explicará de forma breve y general los modelos de elección binaria utilizados en la presente investigación.

\section{Modelos de elección binaria}

Con el objetivo de evaluar el efecto de las diferencias en materia de calidad del empleo en las zonas urbanas y rurales de los departamentos de Colombia sobre la decisión de migrar de la PEA 
colombiana, se decidió hacer uso de modelos de elección binaria, logit y probit. Este tipo de modelos toman como variable endógena una variable dicotómica que puede tomar el valor 1 o 0 , lo cual permite indicar la probabilidad de ocurrencia de un fenómeno de acuerdo a un conjunto de variables explicativas. De forma generalizada se presenta el modelo a continuación donde las variables explicativas son denotadas por el conjunto $q_{j}$ y $\alpha$ denota la constante, la cual según Train (2009) expresa el impacto de los factores no observados sobre la probabilidad de ocurrencia del fenómeno.

$$
P_{i}= \begin{cases}1 & \text { si } \alpha+b_{j} q_{j}>0 \\ 0 & \text { si } \alpha+b_{j} q_{j}<0\end{cases}
$$

La elección del modelo a utilizar se realiza teniendo en cuenta la distribución supuesta de los errores; ya que si se supone una distribución uniforme es habitual la utilización de un Modelo Lineal de Probabilidad MLP. Por otro lado, si se asume que los factores no observados están incorrelacionados con las variables observadas, se utiliza una curva logística propia de un modelo Logit, y en cambio si se comprueba que los errores se distribuyen de forma normal se escogería un modelo Probit (Medina, 2003; Train, 2009).

En este sentido, el modelo probabilístico tomaría la siguiente forma:

$$
\begin{aligned}
& P(Y i=1)=P\left(\alpha+b_{j} q_{j}>0\right)=F\left(\alpha+b_{j} q_{j}\right) \\
& P(Y i=0)=P\left(\alpha+q_{j} q_{j}<0\right)=F\left(\alpha+b_{j} q_{j}\right) \\
& P(Y i=0)=1-P\left(\alpha+q_{j} q_{j}>0\right)=F\left(\alpha+b_{j} q_{j}\right)
\end{aligned}
$$

En el presente estudio se decidió estimar modelos de probabilidad no lineal, específicamente un Logit y un Probit. Esta decisión fue tomada con el objetivo comparar los resultados obtenidos con diferentes distribuciones para los errores. En el caso de los modelos Logit, estos utilizan la función de distribución logística, la cual se caracteriza por presentar la siguiente forma:

$$
F\left(\alpha+b_{j} q_{j}\right)=P_{i}=\frac{e^{\alpha+b_{j} q_{j}}}{1+e^{\alpha+b_{j} q_{j}}}+e_{j}=\frac{1}{1+e^{-\alpha-b_{j} q_{j}}}+e_{j}
$$

Al definir la razón de probabilidades (odds ratio) y tomar su logaritmo natural, se puede obtener la función del modelo Logit Li, la cual se caracteriza por ser lineal en los parámetros $b_{j}$ y las variables $q_{j}$.

$$
L i=\ln \left(\frac{P_{i}}{1-P_{i}}\right)=\alpha+b_{j} q_{j}
$$

En cuanto al modelo probit, este asume una distribución normal tipificada de media cero y varianza uno, es decir $Z_{j} \sim N\left(0, \sigma^{2}\right)$. Donde $F\left(\alpha+b_{j} q_{j}\right)$ es la función de distribución normal acumulada con la siguiente especificación:

$$
F\left(\alpha+b_{j} q_{j}\right)=\left(\frac{1}{\sqrt{2 \pi}}\right) \int_{-\infty}^{\alpha+b_{j} q_{j}} e^{-z^{2} / 2} d z+e_{i}
$$


Es importante recordar que existe una estrecha similitud entre la curva logística definida por la ecuación [12] y la curva normal estandarizada definida por [14]. Por tal motivo, los resultados provistos por ambas no difieren de manera significativa entre sí y su diferencia principal es el método operativo para estimarlas.

En el presente estudio, los modelos Logity Probit estimados toman como variable dependiente una binaria que obtiene el valor (1) si la persona ha migrado en los últimos 12 meses y (0) si la persona es residente de la zona por más de 12 meses. Por otro lado, la mencionada elección de migrar se intenta explicar por medio de los subíndices referentes a las dimensiones del ICCE de la zona de origen ${ }^{11}$ del/a migrante, de acuerdo con las siguientes ecuaciones.

$$
\begin{aligned}
& \operatorname{logit}(\text { migra })=\beta_{0}+\beta_{1} \text { satis }_{i}+\beta_{2} \text { genero }_{i}+\beta_{3} \text { sayse }_{i}+\beta_{4} \text { inclu }_{i}+\beta_{5} \text { dial }_{i}+\beta_{6} \text { establ }_{i} \\
& +\beta_{7} \text { jorlab }_{i}+\beta_{8} \text { ingreyga }{ }_{i}+\beta_{9} \text { mujer }+\beta_{10} \text { Jefe }+\beta_{11} \text { Tamaño }+\beta_{11} \text { Tiempo } \\
& +\beta_{12} \text { Edad }+\beta_{i} \text { Dpto }_{i} \\
& \operatorname{probit}(\text { migra })=\beta_{0}+\beta_{1} \text { satis }_{i}+\beta_{2} \text { genero }_{i}+\beta_{3} \text { sayse }_{i}+\beta_{4} \text { inclu }_{i}+\beta_{5} \text { dial }_{i}+\beta_{6} \text { establ }_{i} \\
& +\beta_{7} \text { jorlab }_{i}+\beta_{8} \text { ingreyga }{ }_{i}+\beta_{9} \text { mujer }+\beta_{10} \text { Jefe }+\beta_{11} \text { Tamaño }+\beta_{11} \text { Tiempo } \\
& +\beta_{12} \text { Edad }+\beta_{i} \text { Dpto }_{i}
\end{aligned}
$$

Donde migra es una variable binaria que identifica a las personas que migraron en los últimos 12 meses, satis, ${ }_{i}$ es el subíndice para satisfacción, genero ${ }_{i}$ para la equidad de género, sayse $_{i}$ para salud y seguridad social, inclu $_{i}$ para la inclusión al mercado laboral, dial li $_{i}$ para diálogo social entre la empresa y el/la trabajador/a, establ, para estabilidad en el puesto de trabajo, jorla $b_{i}$ para jornada laboral $y$ vida familiar/personal, ingreyg $a_{i}$ para ingreso y ganancias laborales e i para la zona de origen en el año 2014. Por otro lado, como características individuales se incluyó mujer que permite identificar el sexo de los potenciales migrantes, su relación con el lefe del hogar, el Tamaño de su zona de origen, si el Tiempo en su empleo es mayor a un año y su Edad. Así mismo, es importante destacar que se procedió a controlar la varianza entre los departamentos de destino por medio de la inclusión de variables binarias referentes a estos en el sentido de modelos con múltiples interceptos.

Cabe destacar que cada modelo fue estimado con el paquete estadístico Stata 15 y que los detalles de los algoritmos estimados se pueden consultar en las notas metodológicas de la función logit (Stata, 2018a) y probit (Stata, 2018b).

Finalmente, se reconoce que en una siguiente etapa de la investigación puede ser pertinente e incluso recomendable incluir más características individuales de las personas para ajustar el modelo y estimar diversas versiones del ICCE.

\section{RESULTADOS}

\section{Caracterización de los departamentos colombianos}

Colombia presenta una marcada heterogeneidad en cuanto a las características de sus regiones, no solamente en el aspecto urbano-rural, sino también en el interdepartamental, debido a causas históricas como el centralismo político-económico que ha caracterizado al país y la diversidad cultural a lo interno de este.

11 A los/as no migrantes se les asignó el valor de su zona de residencia. 
Dicha heterogeneidad se manifiesta, entre otros aspectos, en las características socioeconómicas de las regiones. En primer lugar, se puede destacar que existe una concentración demográfica en la región andina, pacífico y caribe del país, siendo Bogotá-Cundinamarca, Antioquia, Valle del Cauca, Santander y Atlántico los departamentos más poblados.

Por otro lado, resulta preocupante que el promedio de escolaridad de cada departamento oscila entre los 7 años en La Guajira y hasta los 11 años en Bogotá. Este hecho indica que en promedio la PEA colombiana cuenta con un nivel educativo de secundaria incompleta. Por otro lado, la edad promedio de esta se encuentra acotado entre los 36,8 años en La Guajira hasta los 39,6 años en Caldas. En cuanto a la ubicación de la población, casi el 72\% de la PEA reside en zonas urbanas.

Con respecto a la estructura económica, esta presenta una gran heterogeneidad. Por ejemplo, la participación promedio de la población ocupada en actividades del sector primario es de un 22,2\% a nivel nacional. Sin embargo, departamentos como Boyacá, Caquetá, Cauca, Córdoba, Chocó, Huila, Nariño y Tolima presentan una participación media que ronda el 35,41\%.

Por otro lado, el sector industrial emplea a cerca del 18\% de los trabajadores, aunque Antioquia, Atlántico, Bogotá, Chocó, La Guajira, Risaralda, Santander y Valle del Cauca se ubican por encima de la media nacional y en conjunto exhiben un promedio del 22,14\% de participación de los ocupados en dicho sector.

En cuanto al sector terciario, este emplea al 59,55\% de los trabajadores/as colombianos/as, siendo Antioquia, Atlántico, Bogotá, Bolívar, Cesar, Magdalena, Meta, Norte de Santander, Quindío, Risaralda, Sucre y Valle del Cauca, los departamentos cuya proporción de empleados en dicho sector es más elevada, rondando un $67,23 \%$.

En lo referente al desempleo, Quindío, Chocó, Risaralda, Norte de Santander, Valle del Cauca, Cauca, Nariño y Meta presentan cifras de dos dígitos a pesar de que la media nacional se ubicó en 9,18\%. Por otro lado, La Guajira, Bolívar, Santander y Córdoba exhiben las tasas de desocupación más bajas del país.

No obstante, a pesar de que las anteriores estadísticas descriptivas ilustran resultados interesantes sobre el mercado laboral de los departamentos colombianos, estas ocultan información relevante sobre la calidad del empleo y la calidad de vida de estos. Por ejemplo, La Guajira exhibe la menor tasa de desocupación; sin embargo, su Índice Compuesto de Calidad del Empleo (ICCE) se encuentra posicionado en 52 unidades ${ }^{12}$ por debajo de la media nacional. Estos resultados serán analizados de una forma más detallada en la siguiente sección.

\section{Calidad del empleo}

En el presente estudio se estimó un Índice Compuesto de Calidad del Empleo (ICCE) como una sumatoria de los subíndices referentes a ocho dimensiones del empleo de calidad. Dichos subíndices fueron construidos a partir de cuarenta y nueve indicadores, los cuales son descritos en la subsección del marco teórico. Debido a que se diferenciaron las zonas rurales y urbanas, los índices se construyeron de forma independiente para cada una, lo cual generó un importante volumen de datos, específicamente ocho subíndices y un ICCE para veinticuatro zonas urbanas y veinticuatro zonas rurales, generando un total de 432 datos entre subíndices y el ICCE.

Dado el amplio volumen de datos y en vista de que el objetivo principal del presente artículo no es realizar un diagnóstico exhaustivo de la calidad del empleo en las zonas urbanas y rurales de los departamentos de Colombia, el análisis en la presente sección se limitará a destacar tendencias generales en este aspecto. No obstante, todos los resultados se encuentran en los anexos para consulta del lector o lectora.

Es importante destacar que cada indicador fue estandarizado con respecto al promedio nacional. En tal sentido, la media nacional es cero para todos los índices y subíndices. Sin embargo, en vista de que dicho promedio fue elaborado teniendo en cuenta la cantidad de observaciones de la muestra

12 Es importante destacar que, con el fin de apreciar de una forma más precisa las diferencias en materia de calidad del empleo, los valores estandarizados de los indicadores fueron multiplicados por 10.los valores estandarizados de los indicadores fueron multiplicados por 10 . 


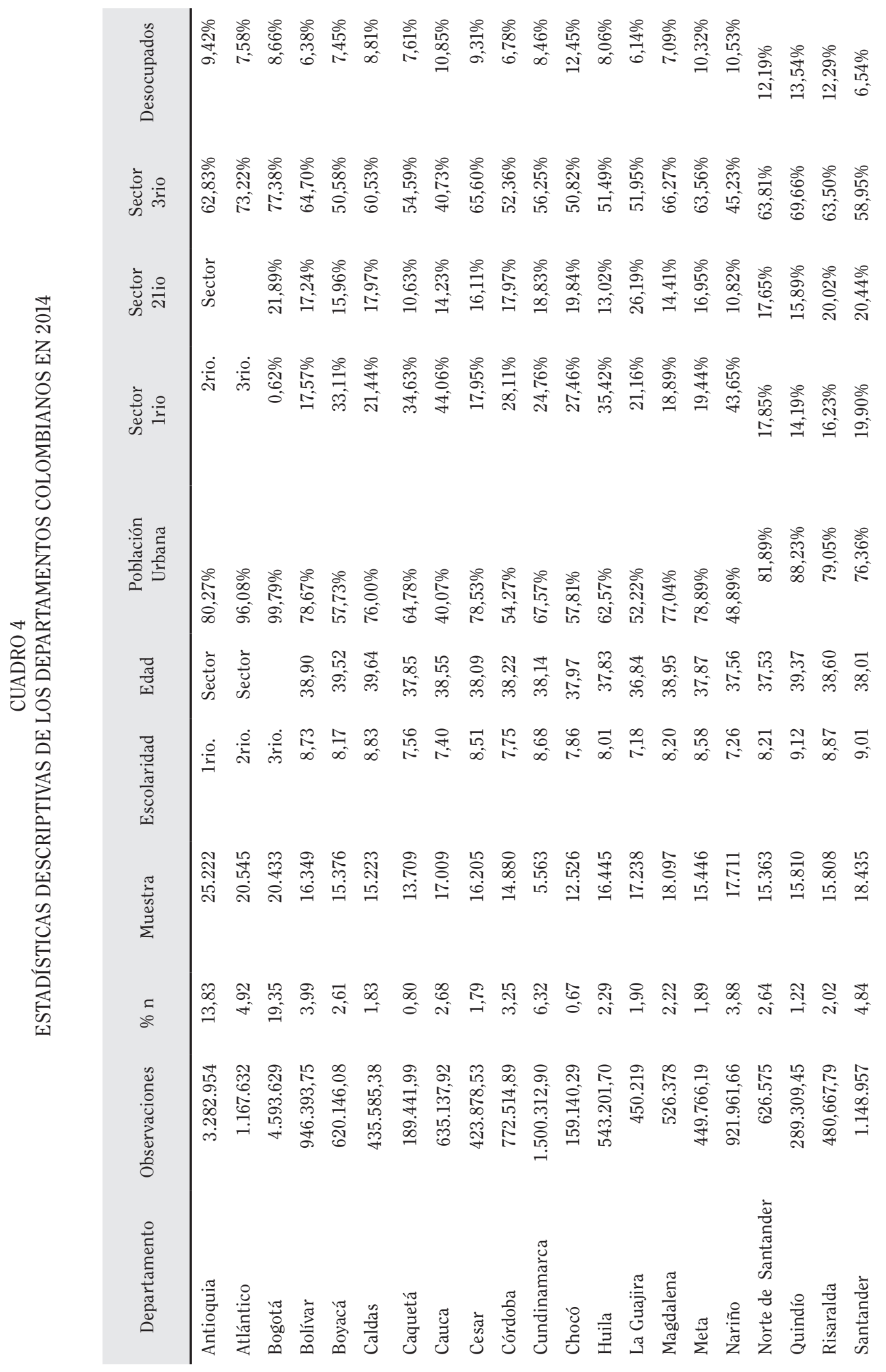




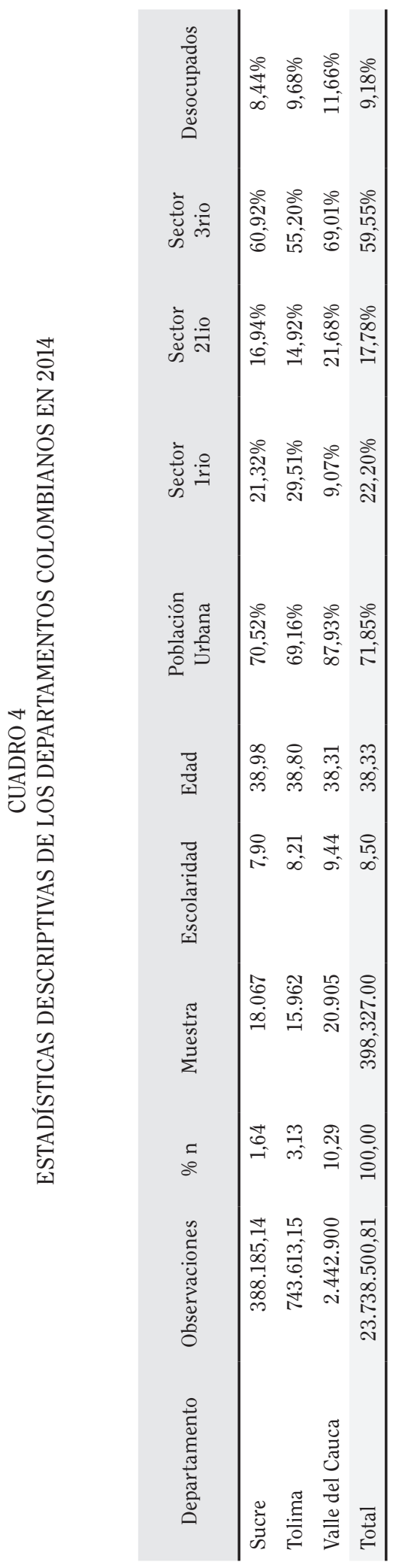


(lo cual implica una ponderación de acuerdo con el tamaño de las áreas urbanas y rurales), cuando se calcula un promedio para las zonas urbanas y rurales, asumiéndolas como unidades individuales homogéneas, el promedio urbano y rural se diferencia de cero, debido a la ausencia de una ponderación de acuerdo al tamaño de estas.

En tal sentido, la figura 1 muestra el promedio de los subíndices referentes a calidad del empleo para las zonas urbanas y rurales de los departamentos de Colombia, asumidas como unidades individuales, homogéneas y sin establecer ninguna ponderación.

En dicha figura se puede observar, por consiguiente, que existe una importante brecha en cuanto a los subíndices concernientes a las dimensiones del empleo de calidad. Entre los resultados más interesantes destaca que la equidad de género, a pesar de estar por debajo del promedio nacional tanto en las zonas urbanas como rurales, en estas últimas el valor es más alto. Este hecho se debe a que las brechas entre hombres y mujeres en cuanto a trabajo formal, salarios y tasa de ocupación tienden a ser menores en las zonas rurales; sin embargo, hay que recordar que este aspecto se refiere únicamente a la equidad de género; ya que si bien en las zonas rurales existe más equidad de género también existen menores salarios, mayor desempleo e informalidad, es decir, a pesar de que las zonas urbanas sean más desiguales en términos de género existe una mayor dispersión de los ingresos, formalidad y tasa de ocupación.

En cuanto a la jornada laboral, las zonas rurales presentan un índice superior a la media nacional, porque existe una mayor proporción de personas que declaran que su jornada laboral es compatible con su vida familiar, existe una menor proporción de personas que desean trabajar menos horas a la semana y una mayor proporción que trabajan menos de 40 horas porque así lo desean. Sin embargo, en las zonas urbanas se observa una mayor proporción de personas que trabajan una jornada completa. Estos hechos son coherentes con la realidad del campo colombiano y con la flexibilidad de las jornadas laborales. Por tal razón, no es de extrañar que en estas áreas el subíndice para la jornada laboral sea superior al de las zonas urbanas.

CUADRO 3

DEPARTAMENTOS SELECCIONADOS PARA EL ESTUDIO

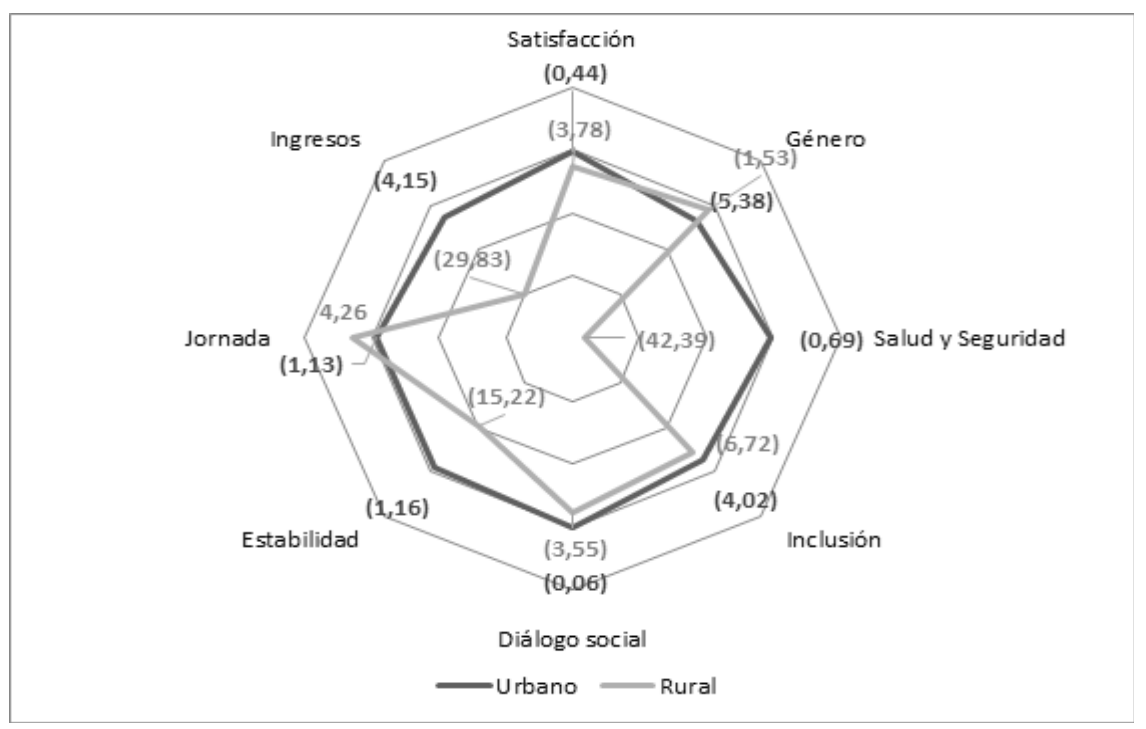

Fuente: Elaboración propia con datos del DANE. 
Por otro lado, resulta preocupante que las brechas más importantes entre las zonas urbanas y rurales sean en los subíndices de salud y seguridad social, ingresos y ganancias laborales, y estabilidad en el empleo. Esto refleja la extrema vulnerabilidad a la pobreza de las personas en las regiones rurales y supone un aspecto de preocupación para quienes diseñan y ejecutan políticas públicas.

De igual modo, se observa que las zonas urbanas presentan mejores subíndices en aspectos como la satisfacción con el puesto de trabajo, la inclusión y el diálogo social, aunque con una brecha menor.

De acuerdo con los resultados anteriores, se podría esperar un sostenimiento de los flujos migratorios de zonas rurales a zonas urbanas.

En cuanto a los resultados del ICCE por departamento, en el cuadro 5 se puede destacar que todas las zonas rurales se encuentran por debajo de la media, exceptuando a las zonas rurales de Bogotá. Este resultado refleja un panorama dantesco para dichas regiones.

Cabe destacar que las zonas rurales con mayor calidad del empleo, de acuerdo con el ICCE ${ }^{13}$, se encuentran en los departamentos Meta, Antioquia, Cundinamarca, Valle del Cauca y Caldas, todos en la Región Centro del país. Por otro lado, los que presentan menor calidad del empleo se encuentran en Nariño, Sucre, Huila, Córdoba, La Guajira y Chocó, es decir, en la periferia de Colombia. Así mismo, se puede observar una clara predominancia de la Región Caribe entre las zonas rurales con menor calidad del empleo.

CUADRO 5

CLASIFICACIÓN DE ZONAS URBANAS Y RURALES DEPARTAMENTALES DE ACUERDO AL ICCE DE 2014

\begin{tabular}{|c|c|c|c|c|c|}
\hline DIVIPOLA & Departamento & $\begin{array}{c}\text { IICE } \\
\text { Urbano }\end{array}$ & $\begin{array}{c}\text { Posición } \\
\text { IICE-U }\end{array}$ & $\begin{array}{l}\text { IICE } \\
\text { Rural }\end{array}$ & $\begin{array}{c}\text { Posición } \\
\text { IICE-R }\end{array}$ \\
\hline 05 & Antioquia & 33,08 & 1 & $-36,72$ & 3 \\
\hline 08 & Atlántico & $-1,71$ & 8 & $-75,71$ & 9 \\
\hline 11 & Bolívar & $-16,57$ & 11 & $-123,36$ & 18 \\
\hline 13 & Bogotá & 27,33 & 2 & 26,01 & 1 \\
\hline 15 & Boyacá & 3,24 & 7 & $-85,68$ & 12 \\
\hline 17 & Caldas & 19,26 & 6 & $-61,03$ & 6 \\
\hline 18 & Caquetá & $-33,94$ & 16 & $-116,52$ & 16 \\
\hline 19 & Cauca & $-33,01$ & 15 & $-118,54$ & 17 \\
\hline 20 & Cesar & $-38,79$ & 17 & $-116,11$ & 15 \\
\hline 23 & Córdoba & $-52,61$ & 23 & $-169,77$ & 21 \\
\hline 25 & Cundinamarca & 22,19 & 5 & $-40,79$ & 4 \\
\hline 27 & Chocó & $-38,87$ & 18 & $-125,16$ & 19 \\
\hline 41 & Huila & $-27,06$ & 13 & $-179,78$ & 22 \\
\hline 44 & La Guajira & $-52,61$ & 22 & $-140,08$ & 20 \\
\hline 47 & Magdalena & $-47,39$ & 20 & $-76,46$ & 10 \\
\hline 50 & Meta & $-4,88$ & 10 & $-29,28$ & 2 \\
\hline
\end{tabular}

13 Vale la pena recordar que este fue construido como una sumatoria simple de los subíndices de cada dimensión, por lo cual no se asumió ninguna ponderación. También es importante tener presente que, dado que el índice es una medida que resume los resultados obtenidos, este presenta efectos compensatorios entre sus dimensiones; por tal motivo, un alto ICCE puede ocultar dimensiones con un subíndice bajo. 


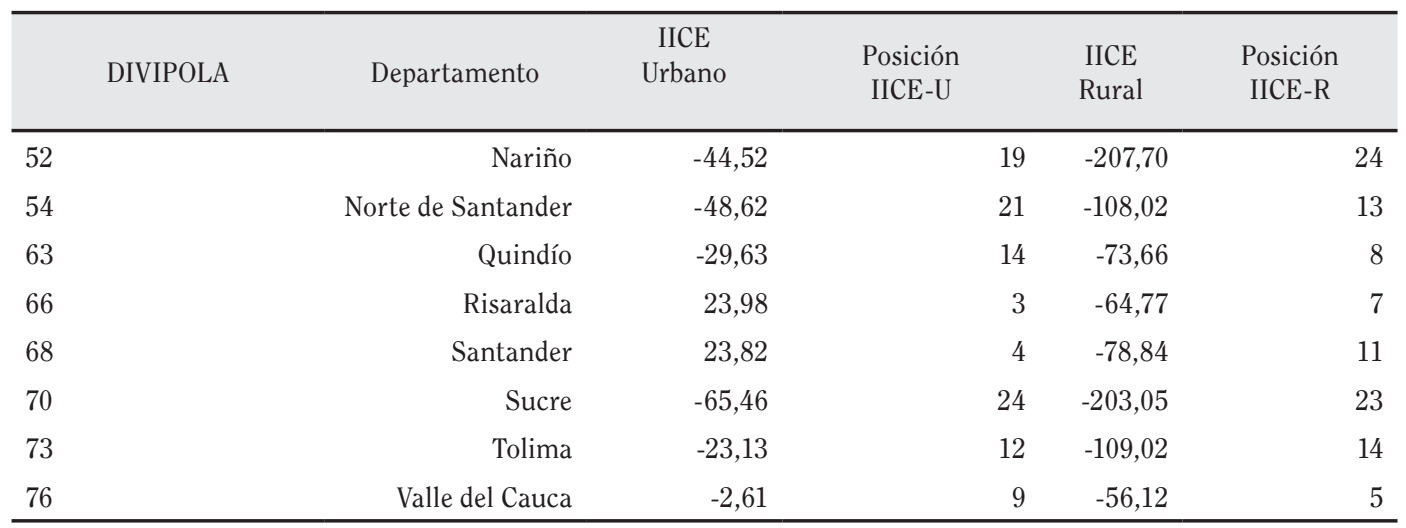

Fuente: Elaboración propia con datos de la GEIH 2014.

Con respecto a la calidad en las zonas urbanas, existen departamentos con un ICCE por encima de la media nacional, estos son: Antioquia, Bogotá, Risaralda, Santander, Cundinamarca, Caldas y Boyacá, pertenecientes a la Región Centro-Andina del país. Por otro lado, entre los que presentaron el menor ICCE, se vuelve a observar una predominancia de la Región Caribe debido a que Sucre, Córdoba, Magdalena y La Guajira vuelven a aparecer en la lista de los departamentos con empleo más precario. A dicha lista se suma Norte de Santander.

Estos resultados demuestran que la Región Caribe merece una especial atención, debido a que tanto sus zonas urbanas como rurales se posicionan entre las que presentan menor ICCE. Por otro lado, debido a la disponibilidad de datos, no se pudo calcular el ICCE para los departamentos de la Región Amazonas ni la Orinoquía, en los cuales se podrían obtener resultados inferiores o preocupantes como los de la Región Caribe.

El autor y la autora recomiendan observar la subsección de Anexos, para que el lector o lectora pueda observar de una forma más detallada cada subíndice y robustecer su perspectiva al respecto.

Por otro lado, al contrastar los resultados obtenidos con los presentados por Quiñones (2011), se debe recordar que estos fueron estimados para años diferentes y que presentan divergencias en su estructura. No obstante, si se asume cierta estabilidad en las brechas interdepartamentales a lo largo del tiempo, efectivamente las zonas urbanas de Antioquia (Medellín) se posicionan como las de mayor calidad del empleo relativo. Sin embargo, las diferencias en los índices generan que la clasificación para las demás zonas urbanas diverja considerablemente, lo cual provoca que los resultados no sean comparables.

\section{Caracterización de la migración interna durante 2014-2015}

De acuerdo con el supuesto del presente estudio, se espera que las personas en zonas con una calidad del empleo por debajo de promedio nacional tengan un incentivo a migrar, ceteris paribis. Por tal motivo y recordando los resultados de la subsección anterior, el lector podría esperar que las tasas de migración neta más bajas se presenten en los departamentos de la Región Caribe, lo cual indicaría una fuerte tendencia a emigrar desde dichas regiones.

El cuadro 6 demuestra que las tasas de migración neta más bajas se presentan efectivamente en la Región Caribe y el Pacífico. Por otro lado, el Quindío, Cundinamarca, La Guajira y Bogotá presentan las tasas más altas de migración neta, es decir, se posicionan como centros receptores de migrantes, lo cual se podría correlacionar con su buen desempeño en la calidad del empleo. No obstante, resulta contraintuitivo el caso de La Guajira, ya que este es uno de los departamentos con menor calidad del empleo; sin embargo, esto se podría explicar si se recuerda que este es uno de los departamentos más pobres de Colombia, razón que influye en que la capacidad de movilidad y desplazamiento de su 
población sea reducido, así mismo, el departamento presenta una alta actividad minera y su cercanía con la frontera podría explicar una mayor tasa de inmigración.

La alta tasa de migración neta del Quindío se puede explicar porque este pertenece al eje cafetero y se ubica a una distancia muy corta con respecto a Caldas y Risaralda; por tal motivo, el alto ICCE de estos últimos puede influir en la migración hacia el Quindío. Es importante realizar una clasificación de los migrantes de acuerdo al sector económico en el cual se desempeñan, debido a que se podría esperar que los migrantes al Eje Cafetero sean personas dedicadas principalmente a actividades agrícolas. Por otra parte, el caso de Cundinamarca y Bogotá se podrían explicar por el tradicional centralismo del país y la atracción que ejerce la capital en los migrantes.

CUADRO 6

MIGRACIÓN INTERDEPARTAMENTAL MENOR A 12 MESES EN COLOMBIA PARA EL AÑO 2015

\begin{tabular}{|c|c|c|c|c|c|c|c|c|}
\hline \multirow[b]{2}{*}{$\begin{array}{l}\text { DIVI } \\
\text { POLA }\end{array}$} & \multirow[b]{2}{*}{ Departamento } & \multirow[b]{2}{*}{ Muestra } & \multicolumn{2}{|c|}{ CALIDAD DE } & \multicolumn{4}{|c|}{ TASA BRUTA } \\
\hline & & & Inmigra & Emigran & $\begin{array}{l}\text { Migración } \\
\text { Neta }\end{array}$ & Inmigra & Emigran & $\begin{array}{c}\text { Tasa } \\
\text { neta de } \\
\text { migración }\end{array}$ \\
\hline 5 & Antioquia & 2.945 .862 & 92.783 & 84.977 & 7.805 & 3,15 & 2,88 & 0,26 \\
\hline 8 & Atlántico & 1.201 .091 & 17.899 & 20.438 & -2.540 & 1,49 & 1,70 & $-0,21$ \\
\hline 11 & Bogotá & 4.451 .844 & 102.950 & 80.854 & 22.096 & 2,31 & 1,82 & 0,50 \\
\hline 13 & Bolívar & 931.049 & 14.004 & 19.729 & -5.725 & 1,50 & 2,12 & $-0,61$ \\
\hline 15 & Boyacá & 667.432 & 24.693 & 29.786 & -5.092 & 3,70 & 4,46 & $-0,76$ \\
\hline 17 & Caldas & 465.641 & 17.612 & 18.020 & -407 & 3,78 & 3,87 & $-0,09 \%$ \\
\hline 18 & Caquetá & 233.581 & 12.973 & 13.119 & -147 & 5,55 & 5,62 & $-0,06 \%$ \\
\hline 19 & Cauca & 638.065 & 18.265 & 26.843 & -8.578 & 2,86 & 4,21 & $-1,34 \%$ \\
\hline 20 & Cesar & 459.716 & 15.216 & 16.955 & -1.739 & 3,31 & 3,69 & $-0,38 \%$ \\
\hline 23 & Córdoba & 686.272 & 5.209 & 18.880 & - 13.671 & 0,76 & 2,75 & $-1,99 \%$ \\
\hline 25 & Cundinamarca & 1.167 .521 & 81.485 & 61.047 & 20.439 & 6,98 & 5,23 & $1,75 \%$ \\
\hline 27 & Chocó & 223.903 & 6.251 & 8.662 & -2.411 & 2,79 & 3,87 & $-1,08 \%$ \\
\hline 41 & Huila & 512.626 & 20.556 & 24.950 & -4.395 & 4,01 & 4,87 & $-0,86 \%$ \\
\hline 44 & La Guajira & 410.587 & 10.466 & 7.405 & 3.061 & 2,55 & 1,80 & $0,75 \%$ \\
\hline 47 & Magdalena & 504.316 & 8.522 & 16.575 & -8.053 & 1,69 & 3,29 & $-1,60 \%$ \\
\hline 50 & Meta & 454.454 & 21.906 & 27.403 & -5.497 & 4,82 & 6,03 & $-1,21 \%$ \\
\hline 52 & Nariño & 898.997 & 20.103 & 18.554 & 1.549 & 2,24 & 2,06 & $0,17 \%$ \\
\hline 54 & N. de Santander & 692.997 & 11.756 & 13.066 & -1.310 & 1,70 & 1,89 & $-0,19 \%$ \\
\hline 63 & Quindío & 367.043 & 26.642 & 20.086 & 6.556 & 7,26 & 5,47 & $1,79 \%$ \\
\hline 66 & Risaralda & 534.944 & 16.170 & 18.224 & -2.053 & 3,02 & 3,41 & $-0,38 \%$ \\
\hline 68 & Santander & 1.163 .720 & 42.444 & 45.355 & -2.911 & 3,65 & 3,90 & $-0,25 \%$ \\
\hline 70 & Sucre & 372.008 & 7.072 & 8.528 & -1.455 & 1,90 & 2,29 & $-0,39 \%$ \\
\hline 73 & Tolima & 703.732 & 39.011 & 35.524 & 3.487 & 5,54 & 5,05 & $0,50 \%$ \\
\hline 76 & V. del cauca & 2.282 .911 & 71.463 & 70.474 & 989 & 3,13 & 3,09 & $0,04 \%$ \\
\hline 0 & Total & 22.970 .310 & 705.452 & 705.452 & 0 & 7,26 & 7,26 & $0,00 \%$ \\
\hline
\end{tabular}

Fuente: Elaboración propia con datos de la GEIH 2014.

Nota: las tasas brutas se calculan como el cociente entre la cantidad de migrantes y la muestra mientras que la tasa neta se estima como la diferencia entre ambas tasas brutas. Los resultados presentados están ajustados por el factor de expansión anual de la base. 
Es importante recordar que existe una amplia gama de razones y variables que motivan la migración interna en Colombia. En tal sentido, el modelo propuesto solamente capta la relación de estas migraciones con respecto al entorno laboral desde la perspectiva de la calidad del empleo, controlando algunas características específicas de los individuos como su género, edad, entre otros.

Adicionalmente, se podría argumentar que la dinámica de expansión y crecimiento de las ciudades intermedias juega un rol capital en esta situación. (Torres y Caicedo, 2015; DNP, 2017)

\section{Modelos de elección binaria (Probit y Logit) estimados}

Con el fin de cumplir con el objetivo de la presente investigación, se estimaron modelos de elección binaria, un Probit y un Logit, en los cuales se toma como variable dependiente una variable dicotómica que identifica a los migrantes, la cual se intenta explicar en términos probabilísticos por los subíndices del ICCE.

Los resultados obtenidos en el cuadro 8 indican que los modelos planteados son significativos al 1\% de acuerdo con la distribución Chi cuadrado y presenta un pseudo R2 de apenas un 0,26.

No obstante, el moderado tamaño del Pseudo R2 del modelo nacional obedece a la simplicidad de este, ya que no se incluyen todas las características individuales de los migrantes ni aspectos como las redes sociales y familiares ni la disponibilidad de servicios en estos. De igual modo, aspectos relevantes como la distancia entre los departamentos pueden provocar un pseudo R2 pequeño, debido a que esta restricción evita que los migrantes puedan maximizar su utilidad migrando hacia las zonas con mayor calidad del empleo. En el mismo orden de ideas, se pudo comprobar que los flujos migratorios bidireccionales también influyeron en este aspecto.

A causa de lo anterior, los autores decidieron controlar el modelo de acuerdo a los destinos seleccionados por los migrantes. Por tal motivo, se estimó el modelo para las zonas urbanas de Antioquia, Bogotá, Boyacá, Caldas, Cundinamarca, Risaralda y Santander, las cuales cuentan con los mejores resultados en cuanto al ICCE. La mencionada decisión excluye el contraflujo migratorio de estas regiones hacia regiones de menor ICCE.

Los resultados del modelo para las ciudades principales también fueron significativos al $1 \%$ y se observó que el pseudo R2 incrementó su tamaño a un 0,5345 en el modelo probit y un 0,5546 en el logit.

En cuanto a los signos, se debe tener presente que, debido a que los índices están normalizados con respecto al promedio nacional, su rango pertenece al conjunto de números reales, incluyendo positivos y negativos. En tal sentido, un parámetro negativo indicaría que existe un mayor estímulo a migrar en las zonas con un subíndice por debajo de la media nacional ${ }^{14}$, mientras que en las ciudades con subíndices positivos ocurre de forma inversa.

CUADRO 7

SIGNIFICADO DEL SIGNO DE LOS PARÁMETROS

\begin{tabular}{lrl}
\hline Signo & Parámetro Negativo & Capital \\
\hline Subíndice Negativo & Mayor Estímulo & Menor Estímulo \\
Subíndice Positivo & Menor Estímulo & Menor estímulo \\
\hline
\end{tabular}

Fuente: Elaboración propia con datos de la GEIH 2015.

14 Estos presentan signo negativo en los subíndices; por lo tanto, el efecto del parámetro negativo genera un mayor efecto positivo en el flujo migratorio desde estas zonas en comparación a aquellas que presentaron valores positivos en los subíndices. 
CUADRO 8

MODELOS DE ELECCIÓN BINARIA (PROBIT Y LOGIT) ESTIMADOS

\begin{tabular}{|c|c|c|c|c|}
\hline & \multicolumn{2}{|c|}{ NACIONAL } & \multicolumn{2}{|c|}{ PRINCIPALES } \\
\hline & Probit & Logit & Probit & Logit \\
\hline Satisfacción con & 0,320 *** & $0,880^{* * *}$ & $2,701^{* * *}$ & $6,381^{* * *}$ \\
\hline el empleo & $(0,019)$ & $(0,046)$ & $(0,251)$ & $(0,712)$ \\
\hline Equidad & $0,783^{* * *} *$ & $2,059 * * *$ & $0,551^{* * * *}$ & 0,297 \\
\hline de género & $(0,016)$ & $(0,041)$ & $(0,124)$ & $(0,369)$ \\
\hline Salud y & $-0,172^{* * *}$ & $-0,455^{* * *}$ & $-6,465^{* * *}$ & $-16,467^{* * *}$ \\
\hline Seguridad Social & $(0,015)$ & $(0,039)$ & $(0,446)$ & $(1,419)$ \\
\hline Inclusión al & $0,459 * * *$ & $1,062 * * *$ & $-7,908 * * *$ & $-21,025^{* * *}$ \\
\hline mercado laboral & $(0,022)$ & $(0,059)$ & $(0,446)$ & $(1,299)$ \\
\hline Diálogo social & $-0,834 * * *$ & $-2,586^{* * *}$ & $-35,118^{* * * *}$ & $-95,049 * * *$ \\
\hline Empresa - Trabajador & $(0,052)$ & $(0,134)$ & $(1,811)$ & $(5,282)$ \\
\hline Estabilidad en el & $0,650 * * *$ & $1,920^{* * *}$ & $-1,033^{* * *}$ & $-4,476^{* * *}$ \\
\hline puesto de trabajo & $(0,035)$ & $(0,093)$ & $(0,388)$ & $(1,279)$ \\
\hline Jornada laboral y & $1,190 * * *$ & $3,679 * * *$ & $-21,009 * * *$ & $-54,552^{* * *}$ \\
\hline vida familiar/personal & $(0,029)$ & $(0,079)$ & $(1,167)$ & $(3,381)$ \\
\hline Ingresos y & $0,407 * * *$ & $1,156^{* * *}$ & $6,856^{* * *}$ & $19,425^{* * * *}$ \\
\hline Ganancias laborales & $(0,021)$ & $(0,053)$ & $(0,441)$ & $(1,390)$ \\
\hline \multirow[t]{2}{*}{ Mujer } & $-0,107 * * *$ & $-0,220 * * *$ & $-0,076^{* * *}$ & $-0,156^{* * *}$ \\
\hline & $(0,011)$ & $(0,024)$ & $(0,023)$ & $(0,057)$ \\
\hline \multirow[t]{2}{*}{ Tamaño de la zona } & $-0,004^{* * *}$ & $-0,010^{* * *}$ & $-0,005^{* * *}$ & $-0,014^{* * *}$ \\
\hline & $(0,000)$ & $(0,000)$ & $(0,001)$ & $(0,002)$ \\
\hline Pareja del jefe & $-0,120 * * *$ & $-0,266^{* * *}$ & $-0,101^{* * *}$ & $-0,260 * * *$ \\
\hline de hogar & $(0,015)$ & $(0,034)$ & $(0,032)$ & $(0,080)$ \\
\hline Hijo del jefe & $-0,456^{* * *}$ & $-0,983^{* * *}$ & $-0,446^{* * *}$ & $-1,090 * * *$ \\
\hline de hogar & $(0,014)$ & $(0,033)$ & $(0,031)$ & $(0,080)$ \\
\hline Nieto del jefe & $-0,508^{* * *}$ & $-1,096^{* * *}$ & $-0,700^{* * *}$ & $-1,703^{* * *}$ \\
\hline de hogar & $(0,040)$ & $(0,093)$ & $(0,115)$ & $(0,311)$ \\
\hline \multirow[t]{2}{*}{ Otro pariente } & $0,188^{* * * *}$ & $0,357^{* * * *}$ & 0,160 *** & $0,302^{* * *}$ \\
\hline & $(0,017)$ & $(0,036)$ & $(0,037)$ & $(0,087)$ \\
\hline \multirow[t]{2}{*}{ Empleado doméstico } & $0,948^{* * *} *$ & $1,870^{* * *}$ & $0,539 * * *$ & $1,216^{* * *}$ \\
\hline & $(0,037)$ & $(0,073)$ & $(0,104)$ & $(0,224)$ \\
\hline \multirow[t]{2}{*}{ Pensionista } & $0,900 * * *$ & $1,685^{* * *}$ & $0,432^{* * * *}$ & $0,899 * * *$ \\
\hline & $(0,083)$ & $(0,160)$ & $(0,213)$ & $(0,425)$ \\
\hline \multirow[t]{2}{*}{ Trabajador } & $0,693^{* * *} *$ & $1,318^{* * *}$ & $0,476^{* * * *}$ & $0,930 * * *$ \\
\hline & $(0,090)$ & $(0,179)$ & $(0,458)$ & $(1,045)$ \\
\hline Otro no & $0,410^{* * * *}$ & $0,780^{* * *}$ & $0,316^{* * * *}$ & $0,606^{* * *}$ \\
\hline pariente & $(0,027)$ & $(0,055)$ & $(0,058)$ & $(0,130)$ \\
\hline
\end{tabular}




\begin{tabular}{|c|c|c|c|c|}
\hline & \multicolumn{2}{|c|}{ NACIONAL } & \multicolumn{2}{|l|}{ PRINCIPALES } \\
\hline & Probit & Logit & Probit & Logit \\
\hline \multirow[t]{2}{*}{ Edad } & $-0,015^{* * *}$ & $-0,031^{* * *}$ & $-0,017^{* * *}$ & $-0,040^{* * *}$ \\
\hline & $(0,000)$ & $(0,001)$ & $(0,001)$ & $(0,003)$ \\
\hline \multirow[t]{2}{*}{ Años en el empleo } & $-0,674^{* * * *}$ & $-1,419 * * *$ & $-0,378^{* * * *}$ & $-0,838 * * *$ \\
\hline & $(0,013)$ & $(0,031)$ & $(0,027)$ & $(0,068)$ \\
\hline \multicolumn{5}{|l|}{ Brecha de calidad } \\
\hline \multirow[t]{2}{*}{ del empleo } & $-0,006^{* * *}$ & $-0,019 * * *$ & $-0,027^{* * *}$ & $-0,071^{* * *}$ \\
\hline & $(0,000)$ & $(0,001)$ & $(0,004)$ & $(0,013)$ \\
\hline \multirow[t]{2}{*}{ Constante } & $0,721^{* * *}$ & 2,357 **** & $5,844^{* * *}$ & $16,906^{* * *}$ \\
\hline & $(0,037)$ & $(0,083)$ & $(0,477)$ & $(1,452)$ \\
\hline $\mathrm{N}$ & 344.751 & 344.751 & 91.406 & 91.406 \\
\hline Chi2 & $26.637,36^{* * *}$ & $30.150,53^{* * *}$ & $16.786,10^{* * * *}$ & $17.414,88^{* * * *}$ \\
\hline P Chi2 & 0 & 0 & 0 & 0 \\
\hline Pseudo R2 & 0,2623 & 0,2968 & 0,5345 & 0,5546 \\
\hline Pseudo R2 & & & & \\
\hline
\end{tabular}

Fuente: Elaboración propia con datos de la GEIH 2015.

Con respecto a los parámetros del modelo nacional, se puede observar que la satisfacción labora, la equidad de género, la inclusión al mercado laboral, la estabilidad, la jornada laboral y el nivel de ingresos presentan valores positivos, lo cual indica que las zonas con índices negativos en estas dimensiones tienden a generar una menor oferta de migrantes. Este hecho resulta coherente, debido a que una baja flexibilidad laboral, una falta de acceso al trabajo, un bajo nivel de ingresos, situaciones de inestabilidad e inequidad de género pueden atar a las personas a sus regiones de origen y reducir su movilidad. Por otro lado, ciudades con niveles positivos en dichas dimensiones pueden proveer a su PEA de mayor libertad y recursos para migrar.

Resulta destacable que el parámetro para Salud y Seguridad Social presente un valor menor a cero; ya que esto indicaría un menor estímulo a migrar en las ciudades que presentan valores positivos en esta dimensión, lo cual indica que los trabajadores aprecian una buena cobertura en salud y seguridad social. Simétricamente, las zonas con bajos índices en salud y seguridad social motivarían a sus habitantes a migrar hacia aquellas regiones con mejores resultados en dicha dimensión. Un análisis similar se podría realizar con el diálogo social.

Adicionalmente, se observa que las mujeres presentan una menor propensión a migrar, así como los familiares cercanos del jefe de hogar. Por otro lado, la edad y contar con más de un año en el puesto de trabajo inciden negativamente en la decisión de migrar.

Así mismo, la brecha en calidad del empleo entre las regiones de origen y destino, en el caso de los migrantes, y entre el 2014 y 2015 para estos y los no migrantes demostró un signo negativo, es decir que a mayor brecha en la calidad del empleo se genera un desestímulo a migrar.

Resulta importante resaltar el valor positivo del intercepto. Este indica que existe una propensión a migrar explicada por otras variables no incluidas en el modelo (Train, 2009), lo cual puede ser explicado por las características socioeconómicas de la población, entre las cuales se podrían citar los lazos familiares, las redes sociales, la pobreza, educación, edad, recursos, entre otros.

Estos resultados niegan parcialmente la hipótesis de la investigación, puesto que, al parecer, la menor calidad del empleo generaría menor migración. Sin embargo, esta aparente conclusión debe matizarse. En primer lugar, se debe recordar que la estandarización de los subíndices fue 
realizada con respecto al promedio nacional y que dadas las características de Colombia, muy pocas zonas se posicionaron por encima del promedio nacional. En segundo lugar, al inspeccionar los Anexos, el lector o lectora podrá confirmar que cerca del 53,6\% de la migración se produce hacia los departamentos con mayor calidad del empleo, es decir, hacia Antioquia, Bogotá, Boyacá, Caldas, Cundinamarca, Risaralda y Santander. En tercer lugar, el 35,7\% del total de la migración se produce entre los mencionados departamentos. Por estas razones, los signos positivos de los parámetros del modelo nacional podrían estar indicando que son los departamentos con una calidad del empleo alta los que generan mayor migración, en comparación a los 17 departamentos restantes.

Por esta razón, se decidió estimar otros modelos controlando la región de destino, es decir, fijando las zonas urbanas de Antioquia, Bogotá, Boyacá, Caldas, Cundinamarca, Risaralda y Santander como las regiones de residencia o destino. Por consiguiente, se mantiene el flujo de los demás departamentos hacia estos, $17,8 \%$ del total de migrantes, $y$ el flujo interno entre estos, 35,7\% del total de migrantes.

Este modelo presentó resultados diferentes al nacional. Específicamente, se puede observar que la equidad de género no fue significativa en el modelo logit y sí lo fue en el probit. Por consiguiente, no se cuenta con un resultado claro sobre la significancia estadística de esta dimensión; sin embargo, ambos modelos indicaron un parámetro positivo para esta, lo cual reforzaría la idea de que la inequidad de género restringe la migración; no obstante, no se puede ofrecer una interpretación concluyente debido a la falta de evidencia que apoye la significancia estadística de esta estimación.

Por otro lado, los coeficientes para satisfacción laboral y nivel de ingresos resultaron ser positivos, es decir que las zonas con mayor satisfacción laboral generarían mayor migración. Este fenómeno aparentemente incoherente se podría explicar por el hecho de que la satisfacción es una medida subjetiva y se encuentra mediada por el entorno. En este sentido, se conoce que contar con un empleo en un entorno precario puede generar una alta satisfacción en vista de que los parámetros de comparación son escasos.

Es interesante que el parámetro para ingresos y ganancias resultó ser positivo, es decir, que en zonas con niveles bajos de esta dimensión existe un desincentivo a migrar, lo cual se puede justificar por la falta de capacidad para asumir los costos de la migración.

Esta apreciación parece confirmarse al observar que los coeficientes de las dimensiones restantes presentaron valores negativos, lo cual es coherente con el supuesto del presente estudio e indica que en efecto las personas deciden migrar, cuando perciben una baja calidad del empleo en sus regiones de origen $y$ tienen las posibilidades de maximizar su utilidad migrando hacia regiones con mejores resultados y donde existan mayores probabilidad de obtener un empleo, donde exista mejor cobertura en seguridad social y jornadas compatibles con la vida familiar.

Por otra parte, se vuelve a confirmar que las mujeres y los familiares cercanos a los jefes de hogar presentan menores probabilidades de migrar. Así mismo, el tamaño demográfico de la zona en la que se habita se correlaciona negativamente con la migración; en este sentido, parece ser más común que se migre desde regiones pequeñas hacia otras más grandes, lo cual confirma el modelo gravitacional.

Teniendo en cuenta el intercepto del modelo, se observa un signo positivo que puede indicar que existe un estímulo no observado a migrar hacia estas ciudades, ya sea por su entorno laboral, calidad de vida, instituciones, infraestructura, cultura, redes familiares y sociales, entre otras. De igual modo, se puede destacar que estas ciudades proveen mejores trabajos, lo cual evita el efecto de retención que suponen los bajos salarios y la inestabilidad laboral. 


\section{Diferencias departamentales en la propensión a migrar}

Con el objetivo de controlar la varianza existente entre los diversos departamentos de destino, se incluyeron variables binarias referentes a cada uno, tomando a Antioquia como departamento de referencia. Con esta acción se pudo establecer diversos interceptos para el modelo. Por consiguiente, a continuación, se presentan los parámetros que junto al intercepto original generan las diversas constantes en el modelo.

Es importante destacar que, en el modelo nacional, los departamentos con mayor constante son Nariño, Quindío, Chocó y Caquetá en comparación con Bolívar, Santander, Atlántico y Bogotá. Además, una mayor constante indica una propensión más alta migrar; en este sentido, se observa que en los departamentos periféricos existe un efecto no observado por el modelo que motiva la migración, entre estos efectos se podría destacar la violencia o la carencia de servicios públicos y diversos bienes, lo cual deja un campo abierto para posteriores investigaciones.

Por otro lado, al inspeccionar las constantes del modelo de ciudades principales, se obtuvo que el orden fue el siguiente: Risaralda, Caldas, Boyacá, Bogotá y Cundinamarca, siendo este último el de menor intercepto, sin contar a Antioquia y Santander, los cuales fueron los departamentos de referencia. En este sentido, el análisis sería similar al del modelo nacional, destacándose que tanto Bogotá como Cundinamarca exhiben un menor incentivo no observado para generar migración, lo cual podría estar relacionado a la condición de capital que tiene Bogotá y su posición al interior de Cundinamarca.

Finalmente, como las variables departamentales fueron significativas en la mayoría de los casos, se justifica la inclusión de las mismas y la estimación de modelos multinivel o de efectos mixtos.

CUADRO 8

MODELOS DE ELECCIÓN BINARIA (PROBIT Y LOGIT) ESTIMADOS

\begin{tabular}{lrllc}
\hline & \multicolumn{2}{c}{ Nacional } & \multicolumn{2}{c}{ Principales } \\
\hline & Probit & Logit & Probit & Logit \\
\hline Atlántico & $-0,7297$ & $-1,7203$ & & $-1,4057$ \\
& 0,0396 & 0,0953 & & 0,6695 \\
\hline Bogotá & $-0,6140$ & $-1,5382$ & $-0,1299$ & \\
\hline Bolívar & 0,0347 & 0,0811 & 0,2403 & 2,4970 \\
& $-2,5718$ & $-8,6309$ & & 0,4338 \\
\hline Boyacá & 0,0473 & 0,1513 & & 4,6005 \\
& $-0,2817$ & $-0,5159$ & 0,7898 & 0,3785 \\
\hline Caldas & 0,0314 & 0,0693 & 0,1622 & \\
& $-0,2894$ & $-0,4698$ & 1,6129 & \\
\hline Caquetá & 0,0372 & 0,0865 & 0,1322 & \\
& 0,8005 & 2,8515 & & \\
\hline
\end{tabular}




\begin{tabular}{|c|c|c|c|c|}
\hline & \multicolumn{2}{|c|}{ Nacional } & \multicolumn{2}{|c|}{ Principales } \\
\hline & Probit & Logit & Probit & Logit \\
\hline \multirow[t]{2}{*}{ Cauca } & 0,6731 & 1,9494 & & \\
\hline & 0,0497 & 0,1268 & & \\
\hline \multirow[t]{2}{*}{ Cesar } & 0,2484 & 1,4042 & & \\
\hline & 0,0490 & 0,1198 & & \\
\hline \multirow[t]{2}{*}{ Córdoba } & $-0,0876$ & 0,0855 & & \\
\hline & 0,0551 & 0,1338 & & \\
\hline \multirow[t]{2}{*}{ Cundinamarca } & $-0,3066$ & $-0,8371$ & $-0,0952$ & $-0,0232$ \\
\hline & 0,0393 & 0,0893 & 0,1188 & 0,3144 \\
\hline \multirow[t]{2}{*}{ Chocó } & 0,8608 & 2,9243 & & \\
\hline & 0,0523 & 0,1359 & & \\
\hline \multirow[t]{2}{*}{ Huila } & 0,4493 & 1,7098 & & \\
\hline & 0,0404 & 0,0937 & & \\
\hline \multirow[t]{2}{*}{ La guajira } & 0,6611 & 2,3017 & & \\
\hline & 0,0427 & 0,1031 & & \\
\hline \multirow[t]{2}{*}{ Magdalena } & 0,0210 & 0,6617 & & \\
\hline & 0,0453 & 0,1085 & & \\
\hline \multirow[t]{2}{*}{ Meta } & 0,0482 & 0,7738 & & \\
\hline & 0,0390 & 0,0906 & & \\
\hline \multirow[t]{2}{*}{ Nariño } & 1,2548 & 4,1711 & & \\
\hline & 0,0504 & 0,1245 & & \\
\hline \multirow[t]{2}{*}{ Norte de Santander } & 0,2739 & 1,4722 & & \\
\hline & 0,0461 & 0,1132 & & \\
\hline \multirow[t]{2}{*}{ Quindío } & 0,8987 & 3,0686 & & \\
\hline & 0,0438 & 0,1061 & & \\
\hline \multirow[t]{2}{*}{ Risaralda } & $-0,4402$ & $-1,0475$ & 2,0122 & 6,7555 \\
\hline & 0,0361 & 0,0864 & 0,1345 & 0,4239 \\
\hline \multirow[t]{2}{*}{ Santander } & $-0,9435$ & $-2,3886$ & Omitida & Omitida \\
\hline & 0,0314 & 0,0721 & & \\
\hline \multirow[t]{2}{*}{ Sucre } & 0,3751 & 1,5806 & & \\
\hline & 0,0488 & 0,1158 & & \\
\hline \multirow[t]{2}{*}{ Tolima } & 0,1772 & 1,0230 & & \\
\hline & 0,0399 & 0,0944 & & \\
\hline \multirow[t]{2}{*}{ Valle del cauca } & 0,4264 & 1,6910 & & \\
\hline & 0,0343 & 0,0808 & & \\
\hline
\end{tabular}

Fuente: Elaboración propia con datos de la GEIH 2015. 
IV.

\section{CONCLUSIÓN}

Es importante destacar que el presente artículo es precursor en la inclusión y estudio de los efectos de la calidad del empleo sobre la migración en el caso colombiano. Por tal motivo, se presentan ciertas posibilidades de mejora y exploración para ajustar las conclusiones obtenidas. No obstante, a pesar de las limitaciones del estudio, se pudieron obtener aproximaciones teóricas y empíricas relevantes que indican el curso a seguir de la investigación.

Entre las limitaciones del presente artículo se pueden destacar que:

1. no se asumió ninguna ponderación para los indicadores constitutivos de las dimensiones de calidad del empleo, para solventar dicho inconveniente, se prevé utilizar Mínimos Cuadrados Parciales en Modelos de Ruta (PLS - PM) y Análisis de Componentes Principales $(\mathrm{ACP})$ en una próxima versión del documento;

2. hace falta incluir mayores indicadores sobre las características individuales de los migrantes que puedan ser relevantes a la hora de tomar la decisión de migrar;

3. el período temporal es reducido, por lo cual no se puede distinguir la migración causada por el retorno a las zonas de origen de las personas; $y$

4. se omiten características como la infraestructura de las regiones, las redes sociales y los costos relativos a migrar.

Sin embargo, entre los resultados obtenidos se pueden destacar que se comprobó y cuantificó la existencia de importantes brechas en los subíndices concernientes a las dimensiones del empleo de calidad entre las zonas urbanas y rurales de diversos departamentos de Colombia.

En la misma línea, resulta interesante que se presentan mejores resultados en cuanto a la equidad de género en las zonas rurales, lo cual se debe a que las brechas entre hombres y mujeres en trabajo formal, salarios y tasa de ocupación tienden a ser menores que en las zonas urbanas; sin embargo, este aspecto se refiere únicamente a la equidad de género y que ello se encuentra correlacionado con el menor rango de ingresos, mayor desempleo e informalidad de estas regiones. Es decir, a pesar de que las zonas urbanas sean más desiguales en términos de género existe una mayor dispersión de los ingresos, formalidad y tasa de ocupación. De igual modo, en cuanto a la jornada laboral, los mejores resultados también se presentan en las zonas rurales debido a la mayor flexibilidad y compatibilidad de estas con la vida familiar y personal de los trabajadores. Sin embargo, en las zonas urbanas se observa una mayor proporción de personas que trabajan una jornada completa. Por otro lado, resulta preocupante que las brechas más importantes entre las zonas urbanas y rurales sean en los subíndices de salud y seguridad social, ingresos y ganancias laborales, y estabilidad en el empleo.

Por otro lado, las zonas urbanas lideran la clasificación con respecto al ICCE. En este sentido, las que muestran mejores resultados son: Antioquia, Bogotá, Risaralda, Santander, Cundinamarca, Caldas y Boyacá, pertenecientes a la Región Centro-Andina del País. En contraparte, los departamentos que presentaron los resultados más precarios fueron los pertenecientes a la Región Caribe. No obstante, es importante recordar que no se cuentan datos para la región amazónica e insular y que los datos para los llanos se encuentran incompletos ${ }^{15}$.

Con respecto a los resultados del modelo, se pudo apreciar que la existencia de flujos migratorios bidireccionales puede afectar la bondad de su ajuste a pesar de que tanto este como las variables utilizadas fueron estadísticamente significativas. Así mismo, la existencia de una fuerte migración interurbana y entre aquellos departamentos que presentan altos índices de calidad del empleo generó la necesidad de estimar un modelo aparte controlando el destino de las migraciones.

15 Solo se tuvo en cuenta al Meta y Caquetá como departamento representante de los Llanos. 
En este sentido, se pudo observar que existen patrones migratorios diferenciados y que la forma en la cual la calidad del empleo influye sobre estos difiere de acuerdo a las regiones tenidas en cuenta.

Por ejemplo, en el modelo nacional la satisfacción en el empleo, la equidad de género, la inclusión al mercado de trabajo, estabilidad del empleo, la jornada laboral y el nivel de ingresos presentan valores positivos en el modelo estimado para las ciudades secundarias y las zonas rurales, lo cual indica que las zonas con índices más bajos en estas dimensiones tienden a generar una menor oferta de migrantes. Este hecho resulta coherente, debido a que una baja flexibilidad laboral, un bajo nivel de ingresos y situaciones de inequidad de género pueden atar a las personas a sus regiones de origen y reducir su movilidad. Por otra parte, el parámetro para Salud y Seguridad Social presentó un signo negativo que indicaría que, en las regiones donde existen bajos niveles de cobertura en estos aspectos, existe un incentivo a migrar por esta razón.

Estos resultados parecen negar la hipótesis de la investigación puesto que, al parecer, la menor calidad del empleo generaría menor migración. Sin embargo, al recordar la forma del índice y el hecho de que más de la mitad de la migración se produce entre los departamentos con alta calidad del empleo, es lógico pensar que los resultados aparentemente contraintuitivos estarían reflejando esta dinámica, es decir, que más del $53,6 \%$ de la migración se realiza hacia las zonas urbanas de los departamentos de mayor calidad del empleo y que el 35,7\% de la migración total se produce a lo interno de estos departamentos.

En este sentido, al estimar el modelo restringiendo los departamentos de destino a aquellas áreas que presentan calidad del empleo por encima del promedio, se pudo observar un cambio en el signo de los parámetros. De modo que se pudo confirmar el signo positivo de las dimensiones como satisfacción con el empleo, equidad de género y nivel de ingresos, las cuales indicarían un desestímulo a la migración en las zonas con niveles de estas por debajo del promedio. Este hecho resulta coherente si se tiene en cuenta que la satisfacción es una variable subjetiva que se encuentra mediada por el contexto y que contar con un empleo, en un escenario de altas carencias laborales, puede generar un alto grado de satisfacción. Así mismo, la equidad de género y el nivel de ingresos indicarían la capacidad de asumir los costos de la migración.

Con respecto a las demás dimensiones, estas presentaron parámetros negativos, lo cual era previsible de acuerdo con la teoría. En este sentido, se confirmaría el estímulo a migrar que generan las carencias en inclusión laboral, jornada laboral, salud y seguridad social, estabilidad del empleo y el diálogo social.

Por otro lado, al observar las características individuales de las personas se puede identificar que las mujeres presentan una menor propensión a migrar, así como la familia cercana del jefe de hogar, destacándose que los parámetros se estimaron con relación a los jefes de hogar quienes obtuvieron el valor de 0 , tras incluir las variables binarias referentes a cada categoría de parentesco.

Así mismo, la edad y el haber trabajado por más de un año en un mismo empleo reducen la probabilidad de migrar de las personas. Esto se puede explicar por la menor aversión al riesgo que se puede sufrir al envejecer y por los mayores costos que supone renunciar a un empleo aparentemente estable.

En cambio, al observar el tamaño relativo de las zonas de origen, se puede observar que, si bien el efecto es negativo, es decir que en las zonas más densamente pobladas hay menores incentivos para migrar, su efecto tiende a ser reducido. Por otro lado, al observar a las personas que no son familia directa del jefe de hogar, se puede evidenciar mayores propensiones a migrar, este hecho se puede deber a que son personas que ya han migrado o que pueden presentar una menor edad relativa $y$, por lo tanto, menor aversión al riesgo.

Por otro lado, se pudo confirmar la existencia de interceptos diferenciados entre los departamentos de Colombia; en este sentido, se confirmó la existencia de efectos no observados por el modelo que estimulan o desestimulan la migración, destacándose el caso de los departamentos periféricos del país, en los cuales la carencia de servicios públicos y la violencia podrían explicar la mayor propensión relativa a migrar. 
Finalmente, existe evidencia empírica que sustenta que las dimensiones de la calidad del empleo son determinantes de la migración interdepartamental en Colombia $y$, posiblemente, a escala internacional. Este resultado expande la teoría de movilidad del factor trabajo al incluir aspectos adicionales a la retribución monetaria del trabajo.

\section{AGRADECIMIENTOS}

El autor y la autora agradecen la colaboración del Departamento Administrativo Nacional de Estadística (DANE) de Colombia y a los profesionales de la Sala Especializada de Procesamiento de Datos por ofrecer la información, orientaciones y bases de datos requeridas para el presente estudio. También agradecen las orientaciones de los docentes del Centro de Investigaciones Económicas Louis Joseph Lebret de la Facultad de Economía y de las facultades de Negocios Internacionales y Gobierno y Relaciones Internacionales de la Universidad Santo Tomás de Colombia. Así mismo, se reconoce el apoyo y orientaciones del Consejo Técnico del Observatorio Latinoamericano de Desarrollo Sostenible OLDS.

\section{REFERENCIAS}

Arranz, J., García-Serrano, C., y Hernaz, V. (2016). Índice de Calidad del Empleo. Madrid: ASEMPLEO. Boccuzzo, G., y Fordellone, M. (2015). Comments about the use of PLS path modeling in building a Job Quality Composite Indicator (Working Paper). Padova: Dipartimento di Scienze Statistiche. Recuperado de http://paduaresearch.cab.unipd.it/8841/

Boccuzzo, G., y Gianecchini, M. (2012). Measuring job quality: a composite indicator. [Rome]: [Italian Statistical Society]. Recuperado a partir de http://meetings.sis-statistica.org/index.php/sm/ sm2012/paper/view/2170/

Boyd, M. (1989). Family and Personal Networks in International Migration: Recent Developments and New Agendas. The International Migration Review, 23(3), 638-670. https://doi. org/10.2307/2546433

Casanueva, C., y Rodríguez, C. (2009). La productividad en la industria manufacturera mexicana: calidad del trabajo y capital humano. Comercio exterior, 59(1), 16-33. Recuperado de http:// revistas.bancomext.gob.mx/rce/magazines/122/2/16_Casanueva-.pdf

CEPAL. (2016). Panorama Social de América Latina 2015. Santiago: Naciones Unidas. Recuperado de http://repositorio.cepal.org//handle/11362/39965

De Jong, G. F., y Fawcett, J. T. (1981). Motivations for Migration: An Assessment and a ValueExpectancy Research Model. En Migration Decision Making (pp. 13-58). Elsevier. https://doi. org/10.1016/B978-0-08-026305-2.50008-5

DNP. (15 de Diciembre de 2017). Atlas de Expansión Urbana Colombia. Departamento Nacional de Planeación. Recuperado de http://atlasexpansionurbanacolombia.org/

Dueñas, D., Iglesias, C., y Llorente, R. (2009). La calidad del empleo en un contexto regional, con espec i a 1 referencia a la Comunidad de Madrid. (Serie Documentos de Trabajo - 05/2009) Universidad de Alcalá. Recuperado de http://www3.uah.es/iaes/publicaciones/DT_05_09.pdf

Engel, S., y Ibáñez, A. M. (2007). Displacement Due to Violence in Colombia: A Household Level Analysis. Economic Development and Cultural Change, 55(2), 335-365. https://doi. org/10.1086/508712

Faist, T. (1997). The crucial meso-level. En T. Hammar, G. Brochmann, K. Tamas, y T. Faist, (Eds.), International Migration, Immobility and Development: Multidissciplinary Perspectives (pp. 187-217). Oxford: Berg.

Farné, S. (2012). La calidad del empleo en América Latina a principios del siglo XXI : una mirada especial a los casos de bolivia, chile, colombia, ecuador y perú. En S. Farné, (Ed.), La calidad 
del empleo en América Latina en el siglo XXI (pp. 15-32). Bogotá: Universidad Externado de Colombia.

Farné, S., y Vergara, C. (2007). Calidad del empleo: ¿qué tan satisfechos estan los colombianos con su trabajo?. Recuperado de http:/www.repository.fedesarrollo.org.co/handle/11445/1747

Farné, S., Vergara, C., y Baquero, N. (2012). La calidad del empleo en medio de la flexibilización laboral. Colombia 2002-2010.

Galvis, L. (2002). Determinantes de la migración interdepartamental en Colombia, 1988-1993. (Documentos de Trabajo sobre economía regional y urbana $29^{\circ}$ ), Banco de la República Colombia. Revuperado de http://www.banrep.gov.co/es/dtser-29

Gómez, M., Galvis-Aponte, L., y Royuela, V. (2015). Calidad de la vida laboral en Colombia: un índice multidimensional difuso. (Documentos de Trabajo sobre Economía Regional y Urbana, $230^{\circ}$ ), Banco de la República - Colombia. Obtenido de http://www.banrep.gov.co/es/dtser-230

Granados, J. (2010). Las migraciones internas y su relación con el desarrollo en Colombia: Una aproximación desde algunos estudios no clasificados como migración interna de los últimos 30 años. (Tesis de Maestría) Universidad Javeriana, Colombia. Recuperado de http://repository. javeriana.edu.co/handle/10554/664

Gutierrez, J., Guzmán, C., y Jiménez, U. (2000). Algunas consideraciones socioeconómicas en torno a las migraciones en Bogotá, 1995-1999. Estudios de Economía y Ciudad - Secretaría de Hacienda de Santa Fe de Bogotá (16), 1-20. Recuperado de http://www.shd.gov.co/shd/sites/default/files/ documentos/estudio16_dee.pdf

Haug, S. (2008). Migration Networks and Migration Decision-Making. Journal of Ethnic and Migration Studies, 34(4), 585-605. https://doi.org/10.1080/13691830801961605

Krugman, P., Obstfeld, M., y Melitz, M. (2012). International Economics - Theory and Policy. New York: Pearson.

López, R., $y$ Schiff, M. (1998). Migration and the Skill Composition of the Labour Force: The Impact of Trade Liberalization in LDCs. The Canadian Journal of Economics / Revue canadienne d'Economique, 31(2), 318-336. https://doi.org/10.2307/136326

Medina, E. (2 de diciembre de 2003). Modelos de elección discreta. Obtenido de www.uam.es/personal_ pdi/economicas/eva/pdf/logit.pdf

Muñoz de Bustillo, R. Fernández-Macías, R., Antón, J., y Esteve, F. (2011). Measuring more than money: the social economics of job quality. Cheltenham, U.K. ; Northampton, Mass: Edward Elgar Publishing. https://doi.org/10.4337/9781849805919

OCDE. (2008). Handbook on constructing composite indicators: methodology and user guide. París: OCDE. https://doi.org/10.1787/9789264043466-en

OIT. (junio de 1999). Trabajo decente. Memoria del Director General en la $87^{\mathrm{a}}$ reunión de la Conferencia Internacional del Trabajo. Ginebra, Suiza: Organización Internacional del Trabajo. Obtenido de http://www.ilo.org/public/spanish/standards/relm/ilc/ilc87/rep-i.htm

OIT. (14 de abril de 2008). 18a Conferencia Internacional de Estadísticos del Trabajo [Conferencia]. Recuperado de http:/www.ilo.org/global/statistics-and-databases/meetings-and-events/ international-conference-of-labour-statisticians/WCMS_092026/lang--es/index.htm

Peycheva, D., Wetzels, R., Parent-Thirion, A., y van Houten, G. (2014). Occupational profiles in working conditions: Identification of groups with multiple disadvantages. Recuperado de https://www. eurofound.europa.eu/publications/report/2014/working-conditions/occupational-profiles-inworking-conditions-identification-of-groups-with-multiple-disadvantages

Pineda, J., y Acosta, C. (2011). Calidad del trabajo: Aproximaciones teóricas y estimación de un índice compuesto. Ensayos sobre Política Económica, 29(65), 60-105. Recuperado de http:// repositorio.banrep.gov.co/handle/20.500.12134/6435

Pizzolitto, G. (2006). Distribución de la población y migraciones internas en Argentina: susdeterminantes individuales y regionales, (Tesis de maestría), Universidad de la Plata, Argentina. Recuperado de http://sedici.unlp.edu.ar/handle/10915/3339 
PNUD. (2016). Progreso Multidimensional: bienestar más allá del ingreso. Nueva York: Phoenix Design. Obtenido de http:/www.latinamerica.undp.org/content/rblac/es/home/library/human_ development/informe-regional-sobre-desarrollo-humano-para-america-latina-y-e/

Pradilla, A. (2016). La efectividad de las reformas laborales sobre el nivel de desempleo. Un análisis del contexto de México y Colombia para el período 2002-2012. Revista CIFE, 18(28), 131-156. https://doi.org/10.15332/s0124-3551.2016.0028.06

Quiñones, M. (2011). El índice de calidad del empleo, una propuesta alternativa aplicada a Colombia. Documento de Trabajo - Universidad del Valle, Cali, Colombia. Obtenido de http://cms. univalle.edu.co/socioeconomia/media/ckfinder/files/DOCUMENTO\%20DE\%20TRABAJO\%20 CIDSE\%20N\%C2\%B0\%20136.pdf

Ravenstein, E. (1885). The laws of migration. Journal of the Statistical Society of London, 48(2), 167235. Obtenido de http://www.jstor.org/stable/2979181

Reinecke G. y Valenzuela, M. (2000). La calidad del empleo: Un enfoque de género. En: Valenzuela, M., y Reinecke, G. (Eds.) ¿Más y mejores empleos para las mujeres? La experiencia de los países del Mercosur y Chile. Santiago: OIT. Recuperado de http:/www.ilo.org/santiago/publicaciones/ WCMS_201292/lang--es/index.htm

Rubiano, N. y Granados, E. (1999). Migraciones internas y violencia en Colombia: el precio de los equilibrios regionales. En: Cubidez y Domínguez (Eds.), Desplazados, migraciones internas y reestructuraciones territoriales. Bogotá: Universidad Nacional, pp.89-103.

Silva, C., y González, P. (2009). Un análisis espacial de las migraciones internas en Colombia (20002005). Revista de la Facultad de Ciencias Económicas, 17(1), 123-144. Recuperado de http:// www.redalyc.org/articulo.oa?id=90913041007

Stark, O. (1991). Migration of Labour. Oxford: Blackwell Publishers.

Stata. (Enero de 2018a). Logit. Obtenido de Stata: https://www.stata.com/manuals13/rlogit.pdf

Stata. (Enero de 2018b). Probit. Obtenido de Stata: https://www.stata.com/manuals13/rprobit.pdf

Todaro, M. (1969). A model of labor migration and urban unemployment in less developed countries. American Economic Review, 59(1), 138-148. Recuperado de http://www.jstor.org/stable/1811100

Todaro, M. (1980). Internal Migration in Developing Countries: A Survey. En R. Easterlin (Ed.), Population and Economic Change in Developing Countries (pp. 361 - 402). Chicago: University of Chicago Press.

Torres, P., y Caicedo, C. (2015). Las ciudades intermediascon mayor potencial en Colombia - Un sistema de identificación. Washington: BID. Recuperado de http://publications.iadb.org/ handle/11319/6890

Train, K. (2009). Discrete Choice Methods with Simulation (2a ed.). Cambridge: Cambridge University Press. https://doi.org/10.1017/CB09780511805271

Weller, J. (2012). Vulnerabilidad, exclusión y calidad del empleo: una perspectiva latinoamericana. Revista Internacional de Estadística y Geografía, 3(2), 82-97. Obtenido de http://www.inegi.org. $\mathrm{mx} / \mathrm{RDE} / \mathrm{RDE} \_06 /$ Doctos/RDE_06_Art6.pdf

Weller, J., y Roethlisberger, C. (2011). La Calidad del Empleo en América Latina. Macroeconomía del Desarrollo, 110. Obtenido de http://hdl.handle.net/11362/5341

Chiang Alpha, C., \& Wainwright, K. (2013). Métodos Fundamentales en Economía Matemática (4 ed.). México: McGrawHill.

DeFusco, R., McLeavey, D., Pinto, J., \& Runkle, D. (2015a). Reading 53 Portfolio Concepts. En CFA Institute (Ed.), CFA Level II Volume 6 Derivatives and portfolio management (pp. 178-186). Charlottesville, USA: WILEY.

DeFusco, R., McLeavey, D., Pinto, J., \& Runkle, D. (2015b). Reading 10 Multiple Regression and Issues in Regression Analysis. En CFA Institute (Ed.), CFA Level II Volume 1 Ethical and professional standards, quantitative methods, and economics (pp. 188-196). Charlottesville USA: WILEY. 
Dumas, B., \& Solnik, B. (1995). The World Price of Foreign Exchange Risk. The Journal of Finance, 50(2), 445-479. https://doi.org/10.2307/2329415

Fama, E., \& French, K. (1993). Common risk factors in the returns on stocks and bonds. Journal of Financial Economics, 33(1), 3-56. https://doi.org/10.1016/0304-405X(93)90023-5

Fama, E. F., \& MacBeth, J. D. (1973). Risk, Return, and Equilibrium: Empirical Tests. Journal of Political Economy, 81(3), 607-636. https://doi.org/10.1086/260061

Gonzales, R. (2011). Riesgo macroeconómico y bolivianización: Un análisis de cointegración con un portafolio dinámico no estacionario de mínima varianza. Revista de Análisis, 15, 9-44.

Gordon J., A., \& Roger D., S. (1980). Consistency of mutual fund performance during varying market conditions. Journal of Economics and Business, 219-226.

Greene, W. (1999). Análisis Econométrico (3ºd.). Madrid: Prentice Hall.

Humerez, J., \& Yañez, E. (2011). Desarrollo del sistema financiero y crecimiento económico, Una aproximación a partir del caso boliviano: 2000-2009. Revista de Análisis, 14, 41-77.

Investopedia. (2017). Short Selling. Obtenido de https://www.investopedia.com/terms/s/shortselling. asp

Jensen, M. (1968). The Performance of Mutual Funds in the Period 1945-1964. The Journal of Finance, 23(2), 389-416. https://doi.org/10.1111/j.1540-6261.1968.tb00815.x

Lintner, J. (1965). Security prices, risk, and maximal gains from diversification. The Journal of Finance, 20(4), 587-615. https://doi.org/10.1111/j.1540-6261.1965.tb02930.x

Markowitz, H. (1952). Portfolio selection. The Journal of Finance, 7(1), 77-91. https://doi. org/10.1111/j.1540-6261.1952.tb01525.x

Peña, D., Tiao, G., \& Tsay, R. (2001). A Course in Time Series Analysis. Nueva York: John Wiley \& Sons Inc.

Pratt, S., \& Grabowski, R. (2010). Cost of capital. Cost of Capital: Workbook and Technical Supplement ( $4^{\circ}$ ed.). California: Wiley.

Ross, S. (1976). The arbitrage theory of capital asset pricing. Journal of Economic Theory, 13(3), 341360. https://doi.org/10.1016/0022-0531(76)90046-6

SAFI BISA. (Abril de 2018). ¿Qué es un fondo de inversión?. Obtenido de http://www.bisasafi.com/ que-es-un-fondo-de-inversion

Sharpe, W. F. (1964). Capital Asset Prices: A Theory of Market Equilibrium under Conditions of Risk. The Journal of Finance, 19(3), 425-442. https://doi.org/10.2307/2977928

Solnik, B., \& Mcleavey, D. (2012). International Asset Princing. En CFA Institute (Ed.), CFA Level II Volume 6, Derivatives and Portfolio Management (pp. 489-497). Pearson.

Stapleton, R. C., \& Subrahmanyam, M. G. (1983). The Market Model and Capital Asset Pricing Theory: A Note. The Journal of Finance, 38(5), 1637-1642. https://doi.org/10.1111/j.1540-6261.1983. tb03846.x

Treynor, J. (1965). How to Rate Management of Investment Funds. Harvard Business Review, XLIII, 63-75.

Vargas, A. (2012). Gestión Activa de Portafolios mediante la aplicación del modelo de Treynor-Black. Revista Investigación \& Desarrollo, 12(1), 17-32. https://doi.org/10.23881/idupbo.012.1-2e

Vijay, S. (2013). Portfolio Risk and Return: Part II. En CFA Institute (Ed.), CFA Level I Volume 4, Corporate Finance and Portfolio Management (pp. 326-365). Charlottesville USA: WILEY.

Vogelsang, T. J. (1999). Two Simple Procedures for Testing for a Unit Root When There are Additive Outliers. Journal of Time Series Analysis, 20(2), 237-252. https://doi.org/10.1111/14679892.00135 
CUADRO 10

SUBÍNDICES DE LAS DIMENSIONES CONSTITUTIVAS DEL ÍNDICE COMPUESTO DE CALIDAD DEL EMPLEO PARA 2014 EN LAS ZONAS URBANAS DEPARTAMENTALES.

\begin{tabular}{|c|c|c|c|c|c|c|c|c|c|}
\hline $\begin{array}{c}\text { Variable } \\
\text { Dependiente }\end{array}$ & Satisfacción & Género & Salud & Inclusión & Diálogo & Estabilidad & Jornada & Ingresos & Calidad \\
\hline Antioquia & 5.82 & -1.07 & 16.55 & -3.30 & 2.47 & 5.29 & -1.80 & 9.12 & 33.08 \\
\hline Atlántico & 7.23 & -7.86 & 10.80 & -8.21 & -1.72 & 3.54 & 2.57 & -8.06 & -1.71 \\
\hline Bogotá & 4.01 & 4.25 & 13.34 & -7.13 & 2.13 & 3.93 & -3.25 & 10.06 & 27.33 \\
\hline Bolívar & 3.29 & -11.77 & -1.72 & -1.70 & -2.59 & 0.91 & 5.56 & -8.56 & -16.57 \\
\hline Boyacá & 1.78 & 0.15 & 3.86 & -5.29 & 2.15 & 0.62 & 0.50 & -0.53 & 3.24 \\
\hline Caldas & 6.92 & -6.58 & 12.89 & -1.32 & 3.41 & 4.62 & -3.56 & 2.88 & 19.26 \\
\hline Caquetá & 5.26 & -10.07 & -8.46 & -6.43 & 1.26 & -5.24 & -4.18 & -6.07 & -33.94 \\
\hline Cauca & -9.21 & -4.83 & -1.46 & -5.74 & -0.14 & -1.17 & -2.15 & -8.32 & -33.01 \\
\hline Cesar & 2.64 & -9.46 & -9.22 & -4.23 & -2.82 & -4.56 & -4.15 & -6.99 & -38.79 \\
\hline Córdoba & -4.39 & -10.69 & -17.24 & -9.73 & -1.88 & 1.68 & 6.65 & -17.01 & -52.61 \\
\hline Cundinamarca & 0.74 & 3.07 & 7.15 & 5.98 & 2.08 & 0.91 & -3.44 & 5.70 & 22.19 \\
\hline Chocó & 9.52 & -8.54 & -5.76 & -17.98 & 3.49 & -4.04 & 0.87 & -16.43 & -38.87 \\
\hline Huila & -8.31 & -6.01 & -2.47 & -4.42 & -0.52 & -2.37 & -1.31 & -1.65 & -27.06 \\
\hline La Guajira & -6.81 & -8.49 & -10.31 & -10.62 & -2.80 & -7.24 & 1.17 & -7.51 & -52.61 \\
\hline Magdalena & -5.19 & -9.94 & -11.83 & -3.89 & -3.73 & -2.60 & -0.25 & -9.97 & -47.39 \\
\hline Meta & 2.37 & -6.69 & 4.66 & 0.12 & 1.02 & -0.12 & -4.12 & -2.10 & -4.88 \\
\hline Nariño & -13.81 & 0.25 & -12.79 & -1.26 & 0.60 & -7.73 & -1.79 & -7.99 & -44.52 \\
\hline $\begin{array}{l}\text { Norte de } \\
\text { Santander }\end{array}$ & -4.75 & -4.31 & -10.27 & -5.70 & -2.34 & -7.00 & -4.10 & -10.16 & -48.62 \\
\hline Quindío & -5.33 & -6.57 & 2.62 & -2.40 & -2.57 & -6.09 & -5.56 & -3.72 & -29.63 \\
\hline Risaralda & 8.55 & -2.09 & 14.12 & -2.83 & 3.01 & 6.36 & -3.25 & 0.12 & 23.98 \\
\hline Santander & 7.44 & -0.63 & 8.14 & 3.37 & 0.50 & 1.61 & 0.23 & 3.15 & 23.82 \\
\hline Sucre & -9.68 & -14.95 & -19.63 & -3.08 & -2.87 & -5.73 & 3.96 & -13.49 & -65.46 \\
\hline Tolima & -6.93 & -3.07 & -5.61 & 1.46 & -0.54 & -2.18 & -2.35 & -3.92 & -23.13 \\
\hline Valle del Cauca & -1.63 & -3.18 & 6.13 & -2.09 & 0.92 & -1.20 & -3.44 & 1.88 & -2.61 \\
\hline
\end{tabular}

Fuente: Elaboración propia con datos de la GEIH 2014. 
FIGURA 2

SUBÍNDICES DE LAS DIMENSIONES CONSTITUTIVAS DEL ÍNDICE COMPUESTO DE CALIDAD DEL EMPLEO PARA 2014 EN LAS ZONAS URBANAS DEPARTAMENTALES

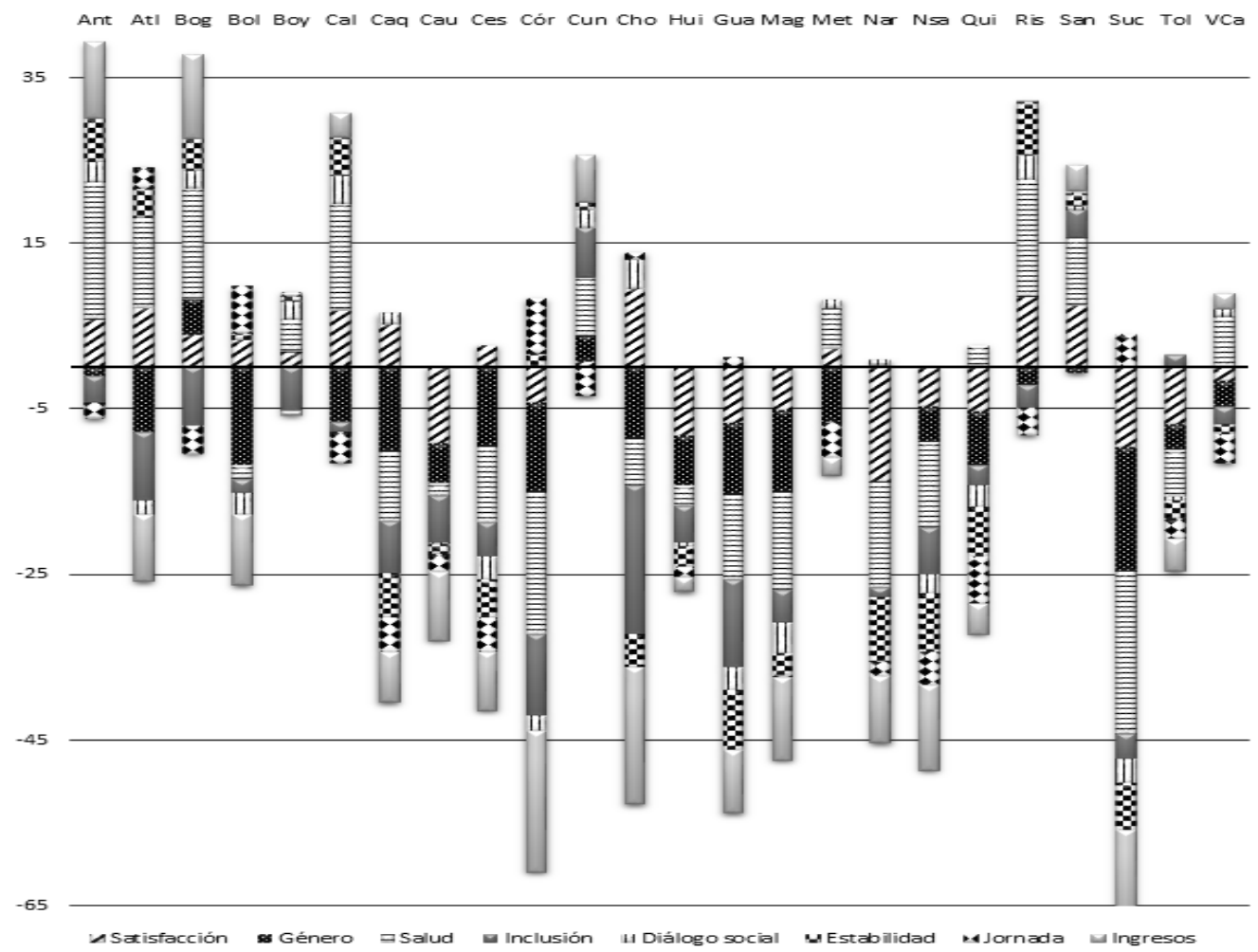

Fuente: Elaboración propia con datos de la GEIH 2014. 
CUADRO 11

SUBÍNDICES DE LAS DIMENSIONES CONSTITUTIVAS DEL ÍNDICE COMPUESTO DE CALIDAD DEL EMPLEO PARA 2014 EN LAS ZONAS RURALES DEPARTAMENTALES.

\begin{tabular}{|c|c|c|c|c|c|c|c|c|c|}
\hline $\begin{array}{c}\text { Variable } \\
\text { Dependiente }\end{array}$ & Satisfacción & Género & Salud & Inclusión & Diálogo & Estabilidad & Jornada & Ingresos & Calidad \\
\hline Antioquia & 5.34 & -9.18 & -15.47 & -4.43 & 0.72 & -4.54 & 3.79 & -12.95 & -36.72 \\
\hline Atlántico & -1.45 & -19.37 & -24.05 & -3.91 & -2.93 & -10.14 & 4.92 & -18.77 & -75.71 \\
\hline Bogotá & -5.62 & 8.30 & -0.62 & 8.13 & -1.86 & 1.08 & 6.81 & 9.80 & 26.01 \\
\hline Bolívar & -3.39 & -4.94 & -57.20 & -9.81 & -7.42 & -17.59 & 8.54 & -31.54 & -123.36 \\
\hline Boyacá & 0.87 & -2.37 & -34.10 & -9.22 & -3.30 & -13.71 & 8.31 & -32.16 & -85.68 \\
\hline Caldas & 11.92 & -5.14 & -18.49 & -5.42 & 3.91 & -11.30 & -6.10 & -30.42 & -61.03 \\
\hline Caquetá & 11.88 & 7.35 & -70.74 & -6.61 & -0.97 & -23.27 & -0.35 & -33.82 & -116.52 \\
\hline Cauca & -20.11 & -2.51 & -39.19 & -13.70 & -7.63 & -12.01 & 10.51 & -33.89 & -118.54 \\
\hline Cesar & -0.97 & -2.24 & -43.51 & -9.43 & -2.86 & -18.83 & -10.91 & -27.35 & -116.11 \\
\hline Córdoba & -19.77 & 7.26 & -86.49 & -14.54 & -7.52 & -16.24 & 10.71 & -43.17 & -169.77 \\
\hline Cundinamarca & -2.66 & 1.87 & -20.91 & 1.50 & -1.79 & -10.04 & 3.57 & -12.33 & -40.79 \\
\hline Chocó & 11.46 & 9.97 & -45.97 & -36.97 & -2.51 & -10.92 & 3.30 & -53.50 & -125.16 \\
\hline Huila & -17.06 & 6.53 & -75.79 & -15.38 & -10.28 & -24.76 & 7.84 & -50.89 & -179.78 \\
\hline La Guajira & -12.38 & 0.16 & -41.46 & -7.60 & -13.73 & -19.53 & 6.19 & -51.74 & -140.08 \\
\hline Magdalena & -1.69 & -3.21 & -30.44 & -4.85 & -3.47 & -5.98 & 0.22 & -27.03 & -76.46 \\
\hline Meta & 4.87 & -4.47 & -12.69 & -1.33 & 2.88 & -7.34 & 0.74 & -11.93 & -29.28 \\
\hline Nariño & -27.77 & -0.37 & -84.95 & -5.47 & -11.19 & -37.55 & 13.51 & -53.90 & -207.70 \\
\hline $\begin{array}{l}\text { Norte de } \\
\text { Santander }\end{array}$ & 2.72 & 7.64 & -57.79 & -3.48 & -2.53 & -22.33 & 7.28 & -39.53 & -108.02 \\
\hline Quindío & -6.32 & -6.25 & -24.06 & -3.42 & -0.34 & -20.20 & 0.00 & -13.09 & -73.66 \\
\hline Risaralda & 3.68 & -3.03 & -25.83 & -8.54 & 2.52 & -12.21 & 1.72 & -23.09 & -64.77 \\
\hline Santander & 4.03 & -3.30 & -39.72 & -0.37 & -5.62 & -12.80 & 7.03 & -28.09 & -78.84 \\
\hline Sucre & -20.62 & -13.02 & -91.12 & -4.64 & -9.60 & -27.15 & 6.81 & -43.71 & -203.05 \\
\hline Tolima & -6.11 & -1.10 & -58.38 & -1.17 & -0.65 & -15.95 & 6.54 & -32.20 & -109.02 \\
\hline Valle del Cauca & -1.66 & -5.25 & -18.33 & -0.56 & 1.02 & -12.02 & 1.33 & -20.65 & -56.12 \\
\hline
\end{tabular}

Fuente: Elaboración propia con datos de la GEIH 2014. 
FIGURA 3

SUBÍNDICES DE LAS DIMENSIONES CONSTITUTIVAS DEL ÍNDICE COMPUESTO DE CALIDAD DEL EMPLEOPARA 2014 EN LAS ZONAS RURALES DEPARTAMENTALES.

Ant Atl Bog Bol Boy Cal Caq Cau Ces Cór Cun Cho Hui Gua Mag Met Na Nsa Qui Ris San Suc Tol VCa

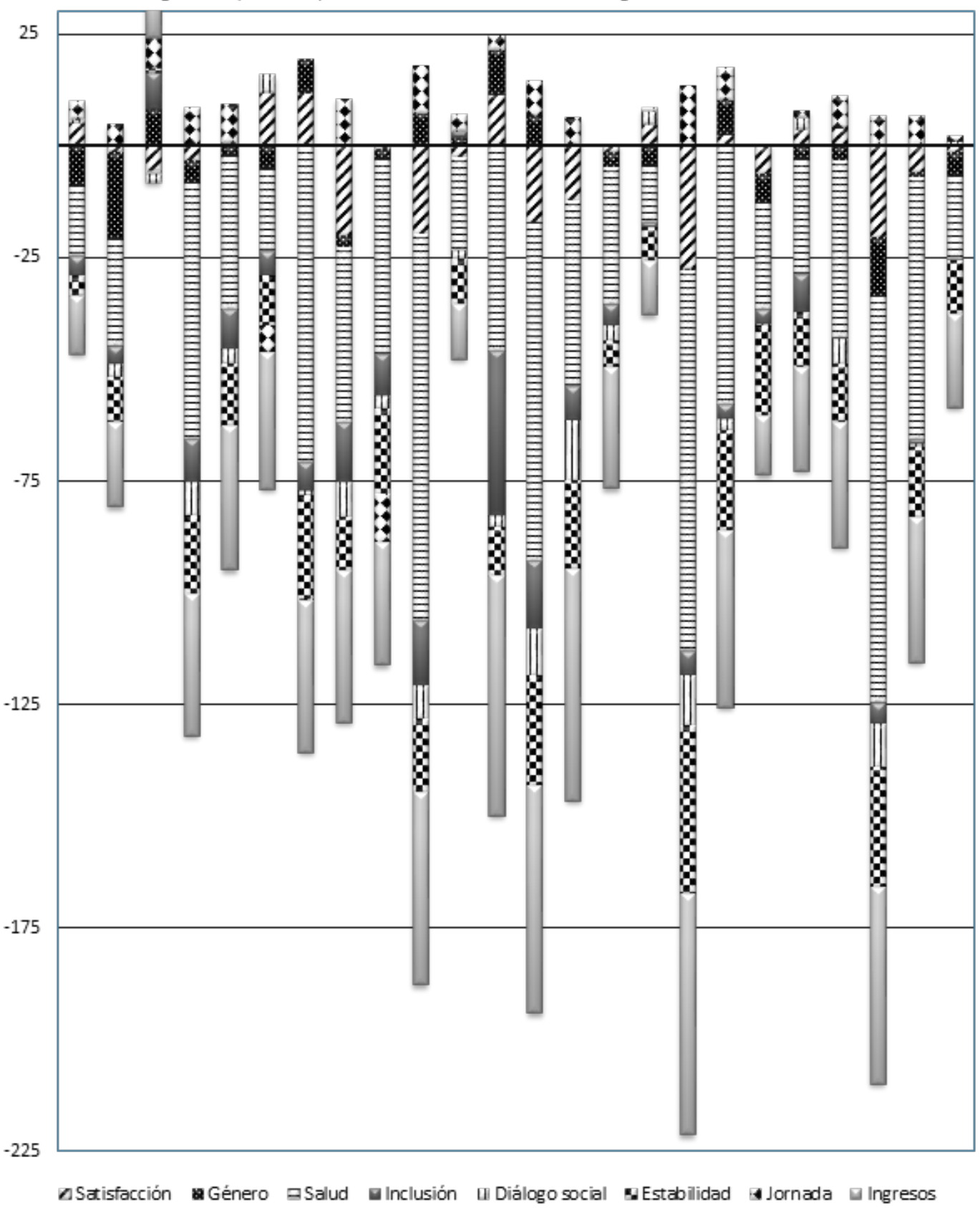

Fuente: Elaboración propia con datos de la GEIH 2014. 


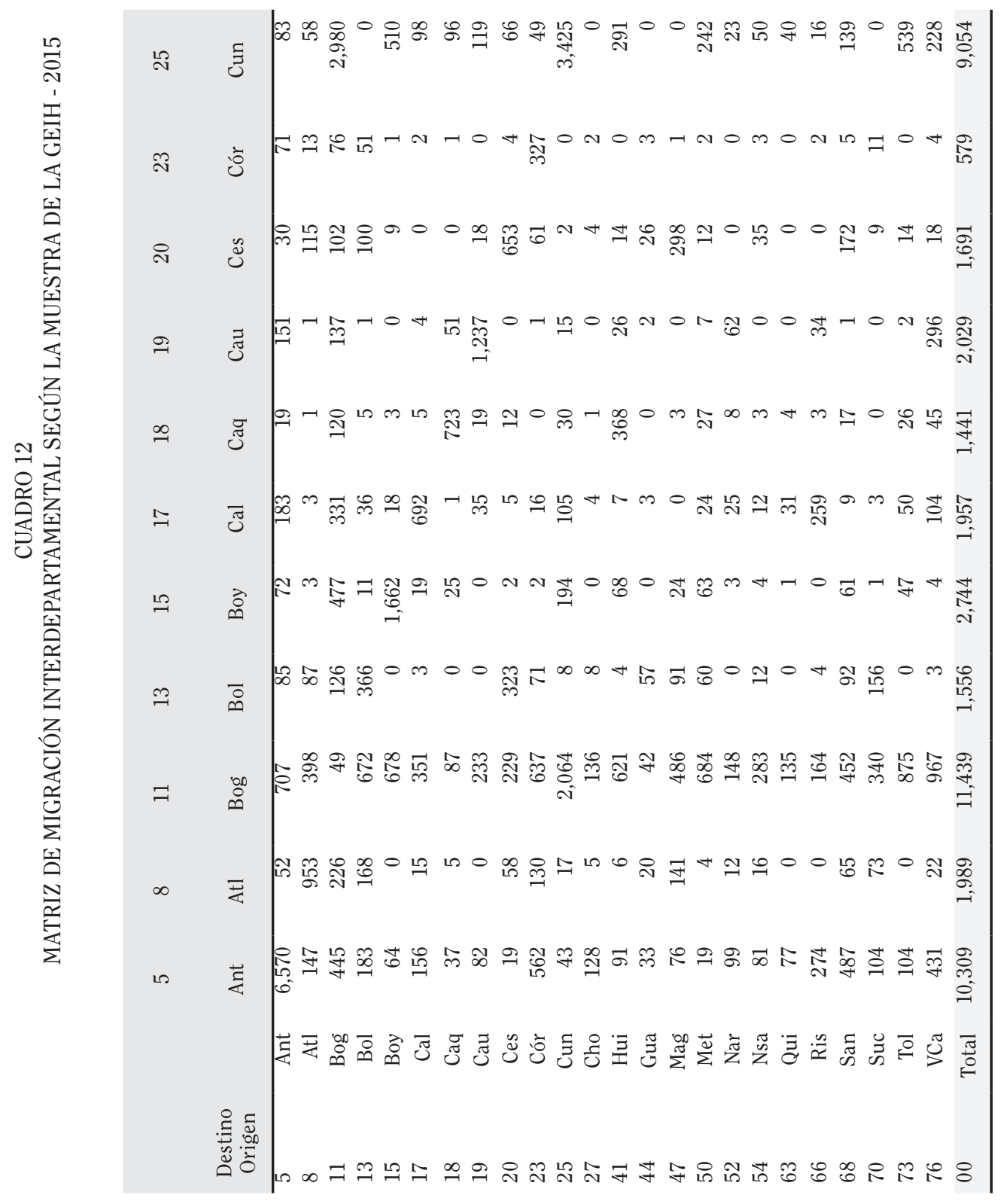




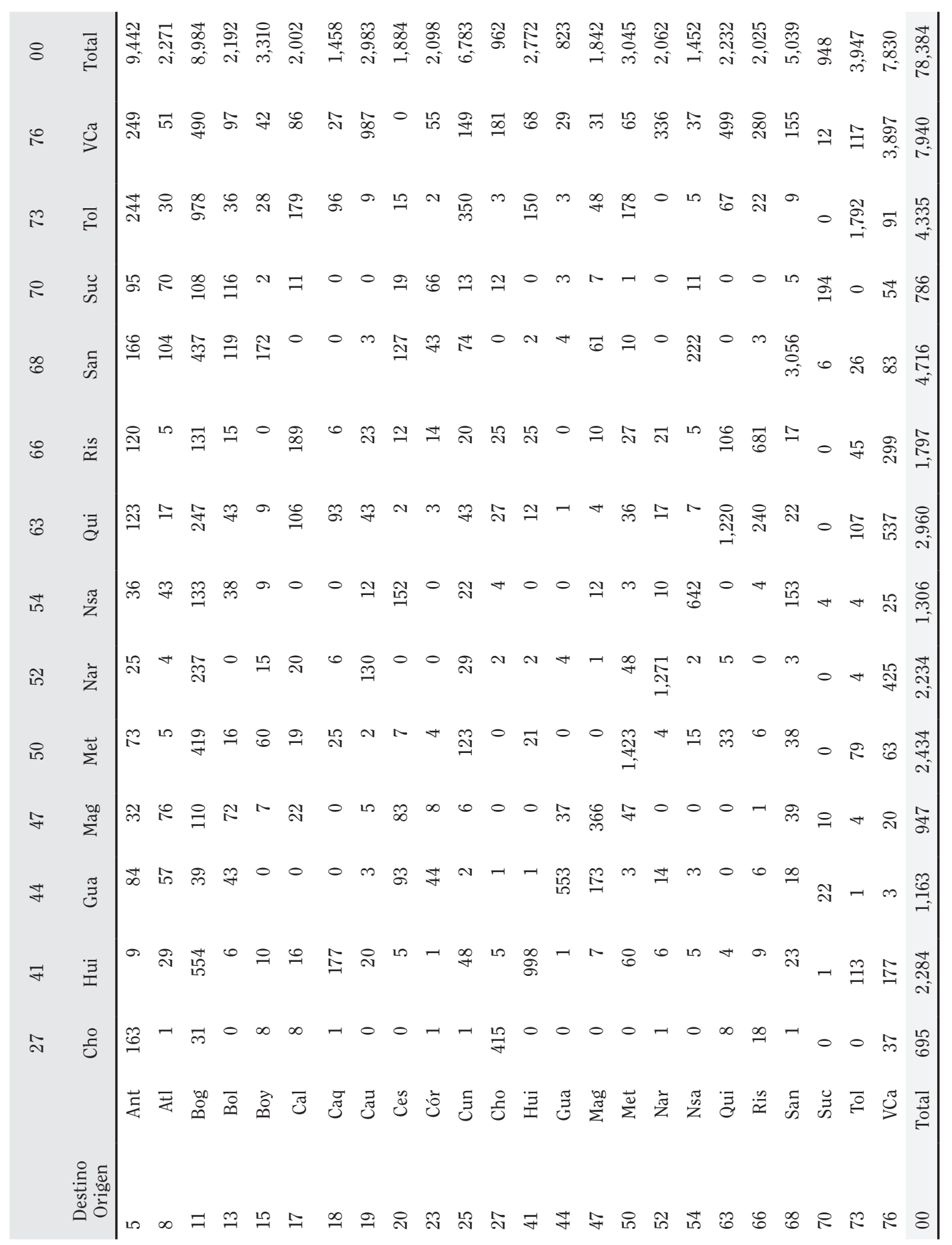


CUADRO 13

MATRIZ DE MIGRACIÓN INTERDEPARTAMENTAL DE 2015 EXCLUYENDO ÁREAS URBANAS CON ALTO ICCE COMO DESTINO.

\begin{tabular}{|c|c|c|c|c|c|c|c|c|c|c|c|}
\hline \multirow[b]{2}{*}{ Destino } & & 8 & 13 & 18 & 19 & 20 & 23 & 27 & 41 & 44 & 47 \\
\hline & & Atl & Bol & $\mathrm{Caq}$ & $\mathrm{Cau}$ & Ces & Cór & Cho & Hui & Gua & Mag \\
\hline 5 & Ant & 52 & 85 & 19 & 151 & 30 & 71 & 163 & 9 & 84 & 32 \\
\hline 8 & Atl & 953 & 87 & 1 & 1 & 115 & 13 & 1 & 29 & 57 & 76 \\
\hline 11 & Bog & 226 & 126 & 120 & 137 & 102 & 76 & 31 & 554 & 39 & 110 \\
\hline 13 & Bol & 168 & 366 & 5 & 1 & 100 & 51 & 0 & 6 & 43 & 72 \\
\hline 15 & Boy & 0 & 0 & 3 & 0 & 9 & 1 & 8 & 10 & 0 & 7 \\
\hline 17 & $\mathrm{Cal}$ & 15 & 3 & 5 & 4 & 0 & 2 & 8 & 16 & 0 & 22 \\
\hline 18 & $\mathrm{Caq}$ & 5 & 0 & 723 & 51 & 0 & 1 & 1 & 177 & 0 & 0 \\
\hline 19 & Cau & 0 & 0 & 19 & 1237 & 18 & 0 & 0 & 20 & 3 & 5 \\
\hline 20 & Ces & 58 & 323 & 12 & 0 & 653 & 4 & 0 & 5 & 93 & 83 \\
\hline 23 & Cór & 130 & 71 & 0 & 1 & 61 & 327 & 1 & 1 & 44 & 8 \\
\hline 25 & Cun & 17 & 8 & 30 & 15 & 2 & 0 & 1 & 48 & 2 & 6 \\
\hline 27 & Cho & 5 & 8 & 1 & 0 & 4 & 2 & 415 & 5 & 1 & 0 \\
\hline 41 & Hui & 6 & 4 & 368 & 26 & 14 & 0 & 0 & 998 & 1 & 0 \\
\hline 44 & Gua & 20 & 57 & 0 & 2 & 26 & 3 & 0 & 1 & 553 & 37 \\
\hline 47 & Mag & 141 & 91 & 3 & 0 & 298 & 1 & 0 & 7 & 173 & 366 \\
\hline 50 & Met & 4 & 60 & 27 & 7 & 12 & 2 & 0 & 60 & 3 & 47 \\
\hline 52 & $\mathrm{Nar}$ & 12 & 0 & 8 & 62 & 0 & 0 & 1 & 6 & 14 & 0 \\
\hline 54 & Nsa & 16 & 12 & 3 & 0 & 35 & 3 & 0 & 5 & 3 & 0 \\
\hline 63 & Qui & 0 & 0 & 4 & 0 & 0 & 0 & 8 & 4 & 0 & 0 \\
\hline 66 & Ris & 0 & 4 & 3 & 34 & 0 & 2 & 18 & 9 & 6 & 1 \\
\hline 68 & San & 65 & 92 & 17 & 1 & 172 & 5 & 1 & 23 & 18 & 39 \\
\hline 70 & Suc & 73 & 156 & 0 & 0 & 9 & 11 & 0 & 1 & 22 & 10 \\
\hline 73 & Tol & 0 & 0 & 26 & 2 & 14 & 0 & 0 & 113 & 1 & 4 \\
\hline 76 & $\mathrm{VCa}$ & 22 & 3 & 45 & 296 & 18 & 4 & 37 & 177 & 3 & 20 \\
\hline 0 & Total & 1989 & 1556 & 1441 & 2029 & 1691 & 579 & 695 & 2284 & 1163 & 947 \\
\hline 76 & $\mathrm{VCa}$ & 22 & 3 & 45 & 296 & 18 & 4 & 37 & 177 & 3 & 20 \\
\hline 0 & Total & 1989 & 1556 & 1441 & 2029 & 1691 & 579 & 695 & 2284 & 1163 & 947 \\
\hline
\end{tabular}


CUADRO 13

MATRIZ DE MIGRACIÓN INTERDEPARTAMENTAL DE 2015 EXCLUYENDO ÁREAS URBANAS CON ALTO ICCE COMO DESTINO.

\begin{tabular}{|c|c|c|c|c|c|c|c|c|c|}
\hline \multirow[b]{2}{*}{ Destino } & & 50 & 52 & 54 & 63 & 70 & 73 & 76 & Total \\
\hline & & Met & Nar & Nsa & Qui & Suc & Tol & $\mathrm{VCa}$ & Total \\
\hline 5 & Ant & 73 & 25 & 36 & 123 & 95 & 244 & 249 & 1541 \\
\hline 8 & Atl & 5 & 4 & 43 & 17 & 70 & 30 & 51 & 1552 \\
\hline 11 & Bog & 419 & 237 & 133 & 247 & 108 & 978 & 490 & 4133 \\
\hline 13 & Bol & 16 & 0 & 38 & 43 & 116 & 36 & 97 & 1156 \\
\hline 15 & Boy & 60 & 15 & 9 & 9 & 2 & 28 & 42 & 205 \\
\hline 17 & $\mathrm{Cal}$ & 19 & 20 & 0 & 106 & 11 & 179 & 86 & 497 \\
\hline 18 & $\mathrm{Caq}$ & 25 & 6 & 0 & 93 & 0 & 96 & 27 & 1205 \\
\hline 19 & Cau & 2 & 130 & 12 & 43 & 0 & 9 & 987 & 2487 \\
\hline 20 & Ces & 7 & 0 & 152 & 2 & 19 & 15 & 0 & 1425 \\
\hline 23 & Cór & 4 & 0 & 0 & 3 & 66 & 2 & 55 & 775 \\
\hline 25 & Cun & 123 & 29 & 22 & 43 & 13 & 350 & 149 & 858 \\
\hline 27 & Cho & 0 & 2 & 4 & 27 & 12 & 3 & 181 & 669 \\
\hline 41 & Hui & 21 & 2 & 0 & 12 & 0 & 150 & 68 & 1668 \\
\hline 44 & Gua & 0 & 4 & 0 & 1 & 3 & 3 & 29 & 740 \\
\hline 47 & Mag & 0 & 1 & 12 & 4 & 7 & 48 & 31 & 1184 \\
\hline 50 & Met & 1423 & 48 & 3 & 36 & 1 & 178 & 65 & 1976 \\
\hline 52 & Nar & 4 & 1271 & 10 & 17 & 0 & 0 & 336 & 1742 \\
\hline 54 & Nsa & 15 & 2 & 642 & 7 & 11 & 5 & 37 & 796 \\
\hline 63 & Qui & 33 & 5 & 0 & 1220 & 0 & 67 & 499 & 1841 \\
\hline 66 & Ris & 6 & 0 & 4 & 240 & 0 & 22 & 280 & 628 \\
\hline 68 & San & 38 & 3 & 153 & 22 & 5 & 9 & 155 & 819 \\
\hline 70 & Suc & 0 & 0 & 4 & 0 & 194 & 0 & 12 & 494 \\
\hline 73 & Tol & 79 & 4 & 4 & 107 & 0 & 1792 & 117 & 2262 \\
\hline 76 & $\mathrm{VCa}$ & 63 & 425 & 25 & 537 & 54 & 91 & 3897 & 5715 \\
\hline 0 & Total & 2434 & 2234 & 1306 & 2960 & 786 & 4335 & 7940 & 36368 \\
\hline 76 & $\mathrm{VCa}$ & 63 & 425 & 25 & 537 & 54 & 91 & 3897 & \\
\hline 0 & Total & 2434 & 2234 & 1306 & 2960 & 786 & 4335 & 7940 & \\
\hline
\end{tabular}

Fuente: Elaboración propia con datos de la GEIH 2015.

Nota: las filas indican el departamento de origen y las columnas el departamento de destino. Valores ajustados por medio del factor de expansión anual de la GEIH. 
CUADRO 14

MATRIZ DE MIGRACIÓN INTERDEPARTAMENTAL DE 2015 CON DESTINO RESTRINGIDO A ARES URBANA CON ALTO ICCE COMO DESTINO..

\begin{tabular}{|c|c|c|c|c|c|c|c|c|c|}
\hline \multirow{2}{*}{\multicolumn{2}{|c|}{ Destino Origen }} & \multirow{3}{*}{$\begin{array}{c}5 \\
\text { Ant } \\
6,570\end{array}$} & \multirow{3}{*}{$\begin{array}{l}11 \\
\text { Bog } \\
707\end{array}$} & \multirow{3}{*}{$\begin{array}{l}15 \\
\text { Boy } \\
72\end{array}$} & \multirow{3}{*}{$\begin{array}{l}17 \\
\text { Cal } \\
183\end{array}$} & \multirow{3}{*}{$\begin{array}{l}25 \\
\text { Cun } \\
83\end{array}$} & \multirow{3}{*}{$\begin{array}{l}66 \\
\text { Ris } \\
120\end{array}$} & \multirow{3}{*}{$\begin{array}{r}68 \\
\text { San } \\
166\end{array}$} & \multirow{3}{*}{$\begin{array}{l}\text { Total } \\
\text { Total } \\
7,900\end{array}$} \\
\hline & & & & & & & & & \\
\hline 5 & Ant & & & & & & & & \\
\hline 8 & Atl & 147 & 398 & 3 & 3 & 58 & 5 & 104 & 719 \\
\hline 11 & Bog & 445 & 49 & 477 & 331 & 2,980 & 131 & 437 & 4,851 \\
\hline 13 & Bol & 183 & 672 & 11 & 36 & 0 & 15 & 119 & 1,036 \\
\hline 15 & Boy & 64 & 678 & 1,662 & 18 & 510 & 0 & 172 & 3,105 \\
\hline 17 & $\mathrm{Cal}$ & 156 & 351 & 19 & 692 & 98 & 189 & 0 & 1,505 \\
\hline 18 & $\mathrm{Caq}$ & 37 & 87 & 25 & 1 & 96 & 6 & 0 & 253 \\
\hline 19 & $\mathrm{Cau}$ & 82 & 233 & 0 & 35 & 119 & 23 & 3 & 496 \\
\hline 20 & Ces & 19 & 229 & 2 & 5 & 66 & 12 & 127 & 459 \\
\hline 23 & Cór & 562 & 637 & 2 & 16 & 49 & 14 & 43 & 1,323 \\
\hline 25 & Cun & 43 & 2,064 & 194 & 105 & 3,425 & 20 & 74 & 5,925 \\
\hline 27 & Cho & 128 & 136 & 0 & 4 & 0 & 25 & 0 & 294 \\
\hline 41 & Hui & 91 & 621 & 68 & 7 & 291 & 25 & 2 & 1,104 \\
\hline 44 & Gua & 33 & 42 & 0 & 3 & 0 & 0 & 4 & 83 \\
\hline 47 & Mag & 76 & 486 & 24 & 0 & 0 & 10 & 61 & 657 \\
\hline 50 & Met & 19 & 684 & 63 & 24 & 242 & 27 & 10 & 1,069 \\
\hline 52 & $\mathrm{Nar}$ & 99 & 148 & 3 & 25 & 23 & 21 & 0 & 320 \\
\hline 54 & Nsa & 81 & 283 & 4 & 12 & 50 & 5 & 222 & 656 \\
\hline 63 & Qui & 77 & 135 & 1 & 31 & 40 & 106 & 0 & 391 \\
\hline 66 & Ris & 274 & 164 & 0 & 259 & 16 & 681 & 3 & 1,397 \\
\hline 68 & San & 487 & 452 & 61 & 9 & 139 & 17 & 3,056 & 4,220 \\
\hline 70 & Suc & 104 & 340 & 1 & 3 & 0 & 0 & 6 & 453 \\
\hline 73 & Tol & 104 & 875 & 47 & 50 & 539 & 45 & 26 & 1,685 \\
\hline 76 & $\mathrm{VCa}$ & 431 & 967 & 4 & 104 & 228 & 299 & 83 & 2,115 \\
\hline Total & Total & 10,309 & 11,439 & 2,744 & 1,957 & 9,054 & 1,797 & 4,716 & 42,015 \\
\hline
\end{tabular}

Fuente: Elaboración propia con datos de la GEIH 2015.

Nota: las filas indican el departamento de origen y las columnas el departamento de destino. Valores ajustados por medio del factor de expansión anual de la GEIH. 